University of Nebraska - Lincoln

DigitalCommons@University of Nebraska - Lincoln

1994

\title{
Size distribution and scattering phase function of aerosol particles retrieved from sky brightness measurements
}

\author{
Y. J. Kaufman \\ NASA Doddard Space Flight Center
}

A. A. Gitelson

Ben Gurion University, agitelson2@unl.edu

A. Karnieli

Ben Gurion University

E. Ganor

Ministry of the Environment and Tel Aviv University

R. S. Fraser

NASA Doddard Space Flight Center

See next page for additional authors

Follow this and additional works at: https://digitalcommons.unl.edu/natrespapers

Part of the Natural Resources and Conservation Commons

Kaufman, Y. J.; Gitelson, A. A.; Karnieli, A.; Ganor, E.; Fraser, R. S.; Nakajima, T.; Mattoo, S.; and Holben, B. $\mathrm{N}$., "Size distribution and scattering phase function of aerosol particles retrieved from sky brightness measurements" (1994). Papers in Natural Resources. 271.

https://digitalcommons.unl.edu/natrespapers/271

This Article is brought to you for free and open access by the Natural Resources, School of at DigitalCommons@University of Nebraska - Lincoln. It has been accepted for inclusion in Papers in Natural Resources by an authorized administrator of DigitalCommons@University of Nebraska - Lincoln. 


\section{Authors}

Y. J. Kaufman, A. A. Gitelson, A. Karnieli, E. Ganor, R. S. Fraser, T. Nakajima, S. Mattoo, and B. N. Holben 


\title{
Size distribution and scattering phase function of aerosol particles retrieved from sky brightness measurements
}

\author{
Y. J. Kaufman, ${ }^{1}$ A. Gitelson, ${ }^{2}$ A. Karnieli, ${ }^{2}$ E. Ganor, ${ }^{3}$ R. S. Fraser, ${ }^{1}$ \\ T. Nakajima, ${ }^{4}$ S. Mattoo, ${ }^{5}$ B. N. Holben 6
}

\begin{abstract}
Ground-based measurements of the solar transmission and sky radiance in a horizontal plane through the Sun are taken in several geographical regions and aerosol types: dust in a desert transition zone in Israel, sulfate particles in Eastern and Western Europe, tropical aerosol in Brazil, and mixed continental/maritime aerosol in California. Stratospheric aerosol was introduced after the eruption of Mount Pinatubo in June 1991. Therefore measurements taken before the eruption are used to analyze the properties of tropospheric aerosol; measurements from 1992 are also used to detect the particle size and concentration of stratospheric aerosol. The measurements are used to retrieve the size distribution and the scattering phase function at large scattering angles of the undisturbed aerosol particles. The retrieved properties represent an average on the entire atmospheric column. A comparison between the retrieved phase function for a scattering angle of $120^{\circ}$, with phase function predicted from the retrieved size distribution, is used to test the assumption of particle homogeneity and sphericity in radiative transfer models (Mie theory). The effect was found to be small $(20 \% \pm 15 \%)$. For the stratospheric aerosol (sulfates), as expected, the phase function was very well predicted using the Mie theory. A model with a power law size distribution, based on the spectral dependence of the optical thickness, $\alpha$, cannot estimate accurately the phase function (up to $50 \%$ error for $\lambda=0.87 \mu \mathrm{m}$ ). Before the Pinatubo eruption the ratio between the volumes of sulfate and coarse particles was very well correlated with $\alpha$. The Pinatubo stratospheric aerosol destroyed this correlation. The aerosol optical properties are compared with analysis of the size, shape, and composition of the individual particles by electron microscopy of in situ samples. The measured volume size distributions before the injection of stratospheric aerosol consistently show two modes, sulfate particles with $r_{m}<0.2 \mu \mathrm{m}$ and coarse particles with $r_{m}>0.7 \mu \mathrm{m}$. The "window" in the tropospheric aerosol in this radius range was used to observe a stable stratospheric aerosol in 1992, with $r_{m} \sim 0.5 \mu \mathrm{m}$. A combination of such optical thickness and sky measurements can be used to assess the direct forcing and the climatic impact of aerosol. Systematic inversion for the key aerosol types (sulfates, smoke, dust, and maritime aerosol) of the size distribution and phase function can give the relationship between the aerosol physical and optical properties that can be used to compute the radiative forcing. This forcing can be validated in dedicated field experiments.
\end{abstract}

\section{Introduction}

Study of the optical and physical properties of aerosol particles is important for assessment of their effect on climate [Charlson et al., 1991, 1992; Kaufman et al., 1991; Penner et al., 1992] and for development of more accurate

\footnotetext{
${ }^{1}$ Laboratory for Atmospheres, NASA Goddard Space Flight Center, Greenbelt, Maryland.

${ }^{2}$ Institute for Desert Research, Ben Gurion University, Sede Boker, Israel.

${ }^{3}$ Institute for Environmental Research, Ministry of the Environment and Tel Aviv University, Sackler School of Medicine.

${ }^{4}$ Center for Climate System Research, University of Tokyo.

${ }^{5}$ ARC-NASA Goddard Space Flight Center, Greenbelt, Maryland.

${ }^{6}$ Laboratory for Terrestrial Physics, NASA Goddard Space Flight Center, Greenbelt, Maryland.

Copyright 1994 by the American Geophysical Union.

Paper number 94JD00229.

0148-0227/94/94JD-00229\$05.00
}

remote sensing procedures of aerosol particles from satellite sensors [Fraser et al., 1984; Tanré et al., 1988a; Kaufman et al., 1990; King et al., 1992; Holben et al., 1992; Dulac et al., 1992]. Tropospheric aerosol particles have a short lifetime (about a week), and as a result their properties vary from one region to another and vary with time. Aerosol concentration and properties depend on the strengths of the sources, on atmospheric processes that affect them, and on transport of the particles from one region to another [Holben et al., 1991]. Because of variability in aerosol properties it is difficult to assess aerosol climatology, since measurements in remote locations, such as taken for $\mathrm{CO}_{2}$ or $\mathrm{CH}_{4}$, cannot be used to represent the aerosol properties. For a full assessment of aerosol characteristics such measurements have to be performed frequently in locations with different aerosol types and in varying meteorological conditions.

Sky brightness and color are determined by scattering and absorption by aerosol particles (solid or liquid particles suspended in the air) and by the atmospheric gases. Molec- 
ular scattering is virtually constant in time. As a result, measurements of the spectral brightness of the sky, in spectral bands where gaseous absorption is minimal, can be used to retrieve information about particle size distribution and optical characteristics [Weinman et al., 1975; Box and Deepak, 1981; Yamamoto and Tanaka, 1969; King et al., 1978; Twitty et al., 1976; Shaw, 1979; Nakajima et al., 1983, 1986a, b; Tanré et al., 1988b; Shiobara et al., 1991]. The characteristics of aerosol particles, retrieved from groundbased measurements, are representative of their properties averaged over the whole atmospheric column. Analysis of the sky brightness, like other remote sensing techniques, retrieves information on the natural undisturbed particles, while in situ measurements subject the particles to changes in the relative humidity between the ambient air and the environment of the instrument. The collection efficiency of the instrument may be a function of the particle size and, therefore, not representing all the particles equally [Huebert et al., 1990]. Sky measurements, used to retrieve the aerosol characteristics are usually taken in the solar almucantar, a horizontal plane passing through the Sun (the view zenith angle is equal to the solar zenith angle).

The main properties of the aerosol particles that are important for climate studies as manifested in recent publications and for remote sensing are (1) size distribution of the aerosol particles, for the different aerosol types (e.g., sulfates, smoke particles, and dust) averaged on the prevailing conditions and as a function of the age of the particles; (2) the scattering phase function at large angles for these aerosol types; (3) the single-scattering albedo of the aerosol particles (a measure of light absorption by the particles); (4) lifetime of the aerosol particles; and (5) the effect of atmospheric processes on the aerosol particles.

Previous studies used skylight in the direction of forward scattering (up to $20^{\circ}-40^{\circ}$ from the Sun) to retrieve the particle size distribution. Large particles contributing mainly at small scattering angles and smaller particles contributing at larger angles. In forward direction the sky brightness is not very sensitive to the particle refractive index, shape, and composition. Therefore the size distribution can be derived with high accuracy for particle radius in the range $0.1 \leq r \leq 8 \mu \mathrm{m}$ [Nakajima et al., 1983, 1986a; Shiobara et al., 1991]. The effect of multiple scattering is also smaller in the forward direction than in the backward direction. No retrievals of the scattering phase function, including scattering angles larger than $90^{\circ}$, were reported in the literature. These are also important, since this angular range of scattering determines the aerosol effect on climate and is used for remote sensing (Wang and Gordon [1993] reported a sensitivity study to derive the phase function and single-scattering albedo from almucantar data). Aerosol scattering at large angles $100^{\circ}-$ $140^{\circ}$ is affected by the particle shape [Pollack and Cuzzi, 1980; Koepke and Hess, 1988; Nakajima et al., 1989]. The backscattering of nonspherical particles is usually less dependent on the scattering angle than for spherical particles. The difference between aspherical and spherical scattering is nearly maximum at an angle of $120^{\circ}$ [Koepke and Hess, 1988; Nakajima et al., 1989], which is used in this study. The retrieval of information from sky radiance at large scattering angles requires accurate correction for the effects of multiple scattering and for the contribution of light reflected from the Earth's surface and scattered downward in the atmosphere. Recently, Nakajima et al. [1983, 1986b] developed and applied [Nakajima et al., 1986a, 1989; Shiobara et al., 1991] an inversion scheme that includes accurate radiative transfer modeling to account for multiple scattering.

In this paper the retrieval procedure of Nakajima et al. [1983] is applied to almucantar measurements acquired in several geographical locations with different aerosol types. The purpose is to learn about the structure and geographical variability of the aerosol size distribution and the corresponding optical properties, including scattering at large scattering angles, in an attempt to evaluate aerosol models that are used in climate and remote sensing studies. The measured aerosol size distribution and single-scattering phase function are compared with in situ samples of the aerosol particles and analysis of the size, shape, and composition of the individual particles [Mamane et al., 1980].

\section{Measurements}

The measurements were performed with a combined sunphotometer/sky radiometer, that can measure both the sky radiance and the attenuated direct sunlight, using the same detector, optics, and spectral filters, by changing the electronic gain between two settings. Eight spectral bands, 10 $\mathrm{nm}$ wide were used: $0.44,0.52,0.56,0.62,0.67,0.78,0.87$, and $1.03 \mu \mathrm{m}$. The sunphotometer/radiometer is a portable, battery-operated instrument that was easily carried from one place to another. The measurements are manual, by pointing the instrument to the specific direction of observation. The instrument was positioned on a rotating table for fast and accurate variation in the azimuth between the solar illumination and the observation directions (the expected error in the azimuthal position, close to the Sun is $\pm 0.3^{\circ}$ ). A special collimator, $50 \mathrm{~cm}$ long, was built to reject stray light. The field of view of the instrument is $1^{\circ}$. Tests indicated that at $2^{\circ}$ from the Sun and beyond, there is no measurable effect of the stray light. Morning and afternoon measurements were performed. Measurements were taken only if local sources of pollution were not evident, so that it is possible to assume that the atmosphere is spatially homogeneous across the lowest 2 to $4 \mathrm{~km}$ of atmosphere where most of the tropospheric aerosol is present. The measurements were restricted to solar zenith angles around $60^{\circ}$, in order to be able to measure the scattering phase function for scattering angles up to $120^{\circ}$.

The measurement sequence includes measurements of transmission of the direct sunlight in order to retrieve the total aerosol optical thickness in the eight spectral bands, followed by measurements of the almucantar sky irradiance in three spectral bands $(0.44,0.62$, and $0.87 \mu \mathrm{m})$, on both sides of the Sun. The sequence was concluded by an additional measurement of the transmitted sunlight. The aerosol optical thickness derived from the transmitted sunlight taken before and after the almucantar measurements were interpolated for the time of the almucantar measurements. Each sequence of measurements took 30-40 min. Almucantar sequence for a single wavelength took about 5 min, requiring that the sky conditions won't change significantly during this period of time. The sky radiances from both sides of the Sun were averaged, and the difference was used to check for atmospheric nonhomogeneities. If the difference between the two parts of the sky was systematically more than $8 \%$ (for scattering angle $\geq 4^{\circ}$ ) then the measurement sequence was discarded. Singular points more 
Table 1. Summary of the Solar Transmission Measurements and Inversion of the Sky Measurements

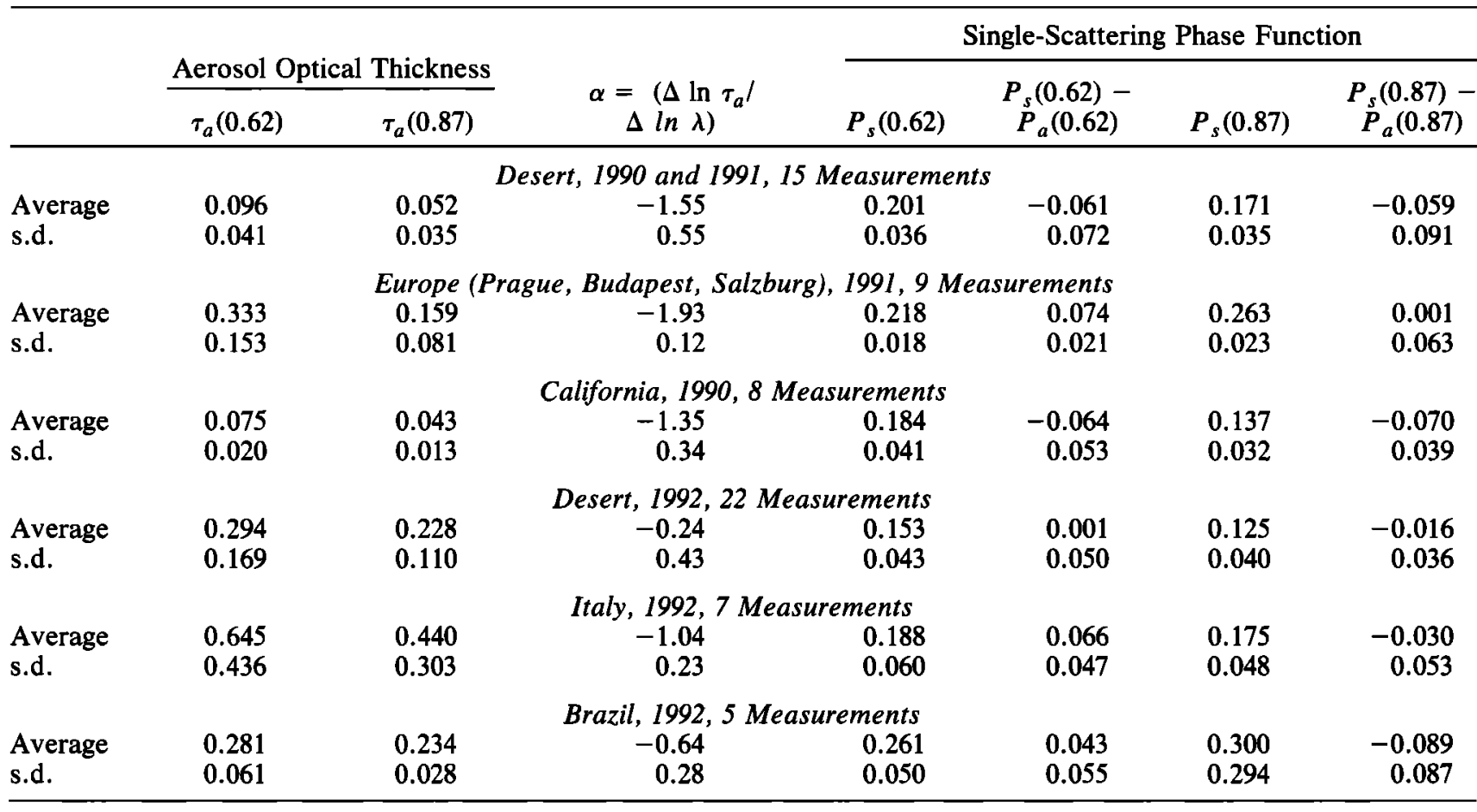

Aerosol optical thickness at $0.62 \mu \mathrm{m}, \tau_{a}(0.62)$ and $0.87 \mu \mathrm{m}, \tau_{a}(0.87)$; the wavelength dependence of the optical thickness $\alpha=\Delta \ln \tau_{a} / \Delta \ln \lambda$ (in the range $0.44-1.03 \mu \mathrm{m}$ ); the phase function at $0.62 \mu \mathrm{m}, P_{s}(0.62)$, and at $0.87 \mu \mathrm{m}, P_{s}(0.87)$, computed from the size distribution assuming spherical and homogeneous particles; the difference between this phase function and the phase function derived from the backscattering sky radiance $P_{a}(0.62)$ and $P_{a}(0.87)$. The phase functions are computed for scattering angle of $120^{\circ}$.

than $8 \%$ off the rest of the curve were also discarded. Sky radiances for a scattering angle of $0^{\circ}-40^{\circ}$ were used to derive the aerosol size distribution, and the whole sky data set was used to derive the aerosol scattering phase function. Polarization was not accounted for but as will be shown in the sensitivity study section, the resulting errors from ignoring polarization are very small. The scattering angle is expressed by the illumination and view zenith angles and the azimuth between the two directions [see, for example, Hansen and Travis, 1974]. The optical thickness measurements in the eight spectral bands were used to derive the Ångström exponent (the slope of $\ln \tau_{a}$ as a function of $\ln \lambda$ ) $\alpha$.

To calibrate the instrument, two calibration procedures were performed. The sky radiances are calibrated to radiance units using the integrating sphere at NASA/GSFC which is traceable to the National Bureau of Standards. The radiances were normalized to reflectance units $\left(\pi L / F_{0}\right)$ where $F_{0}$ is the solar flux [Neckel and Labs, 1984]. The absolute accuracy of the sky radiance measurements is expected to be $\pm 10 \%$. The spectral precision and reproducibility is expected to be $\pm 5 \%$. The sunphotometer measurements were calibrated using a Langley plot technique in clear conditions [see, for example, Kaufman and Fraser, 1983]. The optical thickness is measured with an error of \pm 0.01 to \pm 0.02 . The aerosol optical thickness was derived from the total optical thickness by subtracting the Rayleigh optical thickness and the gaseous absorption optical thickness. In the following we shall describe the main results from the measurements followed by detailed analysis.

\section{Summary of the Results}

Table 1 summarizes the locations and year of the measurements and the key results. The data are averaged for six geographical regions with three different aerosol types: desert aerosol, mainly sulfate particles, and tropical aerosol. In several of these regions we observed the aerosol type using samples of the aerosol particles and electromicroscope analysis. Part of the data sets were collected before the Mount Pinatubo eruption in June 1991 and the enhancement of the stratospheric aerosol layer. The data sets from 1992 are affected by the stratospheric aerosol.

Desert measurements: The data are taken in a desert transition zone in Israel (a semidesert area with low precipitation). Most of the measurements were done at the Israeli Desert Research Institute in Sede Boker. In the first data set, collected during a field experiment in May 1990 and later during continuous measurements from December 1990 till March 1991 (all before the Pinatubo eruption), no major dust outbreaks took place and the aerosol optical thickness $\tau_{a}$ was of background level (average $\tau_{a}=0.10$ at $0.62 \mu \mathrm{m}$ ). Heavy dust at this location is usually associated with a low-pressure system that advects dust from North Africa or from the Arabian Desert. Dust storms from North Africa are more common, with typical trajectories passing over the Mediterranean [Ganor et al., 1991]. This system is accompanied with cloudy conditions, due to the advection of humidity from the maritime air [Mamane et al., 1980]. Therefore almucantar measurements in these conditions are 
basically impossible. Meteorological data show that cloud free conditions are very common in this area between May and October when the cloud fraction is less than $30 \%$ (June to September, the cloud fraction is less than $10 \%$ ). The interaction among desert aerosol, maritime aerosol, sulfates, and clouds was discussed by Levin et al. [1990]. The second data set, collected from January to June 1992 is affected by stratospheric aerosols from the Mount Pinatubo eruption, that increased the average optical thickness from $\tau_{a}(0.62$ $\mu \mathrm{m})=0.10$ to 0.29 and changed the Ångström exponent (the slope of $\ln \tau_{a}$ as a function of $\ln \lambda$ for the eight spectral bands) from -1.5 to -0.2 . This reduction, as will be shown later, is due to the introduction of large stratospheric sulfate particles (average radius of $0.5 \mu \mathrm{m}$ ).

Sulfate aerosol: Two data sets, that are expected to be dominated by tropospheric sulfate aerosol, were collected in Europe. The first in 1990, was collected mainly in Eastern Europe and Austria. The second data set was measured around Lake Maggore in northern Italy in 1992 and therefore is affected also by stratospheric aerosol. The average optical thickness was 0.33 and 0.64 , respectively. The difference is partially due to the contribution of the stratospheric aerosol and partially due to the heavy pollution in northern Italy during the summer in the presence of high humidity. The Ångström exponent changed from -1.9 to -1.0 which can also be associated with the effect of the stratospheric aerosol.

Mixed aerosol: A data set from California, before the eruption, represents a mixture of continental and maritime aerosol with an average optical thickness of 0.07 and Ångström exponent of -1.3 .

Tropical aerosol: A data set from Brazil during the dry season (August 1992) is included. Though the measurements were taken during the dry season, no substantial biomass burning was noticed in the area. The average optical thickness affected by the stratospheric aerosol is 0.28 .

Scattering phase function: Table 1 also indicates the average aerosol scattering phase function for each of the data sets for a scattering angle of $120^{\circ}$. Two phase functions were computed: $\boldsymbol{P}_{s}$, the phase function computed from the derived particle size distribution assuming that the particles are spherical and homogeneous with a given refractive index; $\boldsymbol{P}_{a}$, the phase function computed from the whole almucantar sky radiance (scattering angle ranging from $2^{\circ}$ to $120^{\circ}$ ) by correcting the radiance for multiple scattering, allowing for surface reflection, and subtracting the contribution from molecular scattering. At $120^{\circ}$ we expect the effects of particle nonsphericity to be maximal [Koepke and Hess, 1988]. The effects of size distribution on the phase function are also large at this scattering angle (see Figure 4 for examples).

To derive the phase function $P_{a}$ from the measured sky radiance, we need to correct for multiple scattering and account for the contribution of gaseous scattering and absorption. The procedure is based on the assumption that the optical properties of the aerosol that determine the sky almucantar radiance can be represented by a unique set of single-scattering phase function, $P$, single-scattering albedo, $\omega_{0}$, and optical thickness, $\tau$. For this purpose an "equivalent" size distribution is computed for which the phase function describes correctly the sky radiance for the given aerosol optical thickness. Even though this size distribution is also computed assuming spherical homogeneous particles, it differs from the "true" size distribution derived from the aureole due to the effects of particle nonsphericity on the sky radiance in the backscattering direction. If the reconstructed sky radiance fits the measured sky radiance within the noise in the data (which we found was always the case), then the derived single-scattering phase function should represent the actual aerosol phase function. Phase functions, $P_{s}$ and $P_{a}$, are shown in Table 1 for 0.62 and $0.87 \mu \mathrm{m}$. In the $0.44-\mu \mathrm{m}$ channel a combination of a high detector noise and small fraction of the sky radiance originating from aerosol scattering made this channel not useful for phase function retrievals. The results show that the difference between the two phase functions, $P_{s}$ and $P_{a}$, can be positive or negative and vary between 0 and $30 \%$ of the value of the phase function. An average on all the measurements gives a negligibly small difference. The uncertainties in this difference are discussed later in the detailed analysis of the results. Wang and Gordon [1993] proposed a different scheme to retrieve the phase function (simultaneously with the single-scattering albedo). They also found in a sensitivity study a small effect of calibration errors on the retrieved phase function except for the blue region where it is difficult to retrieve the phase function for small optical thicknesses.

\section{Data Analysis}

The data set, summarized in Table 1 , includes 66 almucantar measurements, with corresponding values of the aerosol optical thickness. Figure 1 shows two examples of the measured almucantar radiances (solid curves) plotted as a function of the scattering angle. These two cases are of extreme conditions of size distributions (shown in Figure 2). The first is of dust in the desert transition zone, with large particles that cause the strong angular dependence of the sky radiance close to the Sun. The second is of an atmosphere with a large concentration of small sulfate particles (in Prague, the Czech Republic) that generates a smaller angular dependence of the sky radiance.

The angular dependence of the almucantar sky radiances for scattering angles less than $40^{\circ}$ are used to compute the aerosol size distribution. In this range of scattering angles the scattering properties are only weakly dependent on the aerosol refractive index and on the sphericity and homogeneity of the particles [Nakajima et al., 1989]. Therefore these radiances are used to retrieve the size distribution of the particles, using the retrieval procedure of Nakajima et al. [1983]. First, the aerosol phase function is derived. Then the aerosol size distribution is derived from the aerosolscattering phase function. Two versions of the procedure are applied to the almucantar data. In the first version the radiances at the three wavelengths are used simultaneously as described by Nakajima et al. [1983, 1986a] and Shiobara et al. [1989]. The resultant size distributions are shown in Figure 2 and the recomputed sky radiance for two of these size distributions is shown by the dashed curves in Figure 1. We found this procedure unsatisfactory for the present set of measurements, since in some cases it resulted in oscillations of the size distribution. The oscillations can result from some variability in the sky conditions during the $30 \mathrm{~min}$ of measurements and from errors in calibration of one spectral band relative to another. Note, however, that this procedure was applied successfully by Nakajima et al. [1983, 1986a] and Shiobara et al. [1989] for data from an automatic instrument 


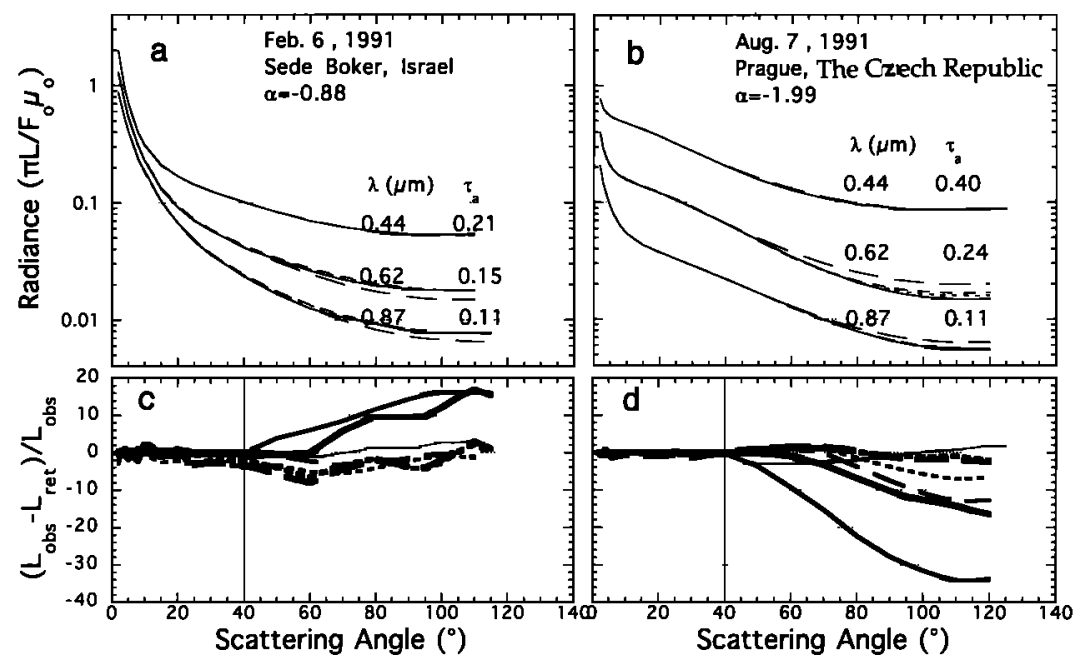

Figure 1. Examples of the measured almucantar sky radiances (solid curves), the recalculated radiance from the derived size distribution (dashed) and from the retrieved single-scattering phase function for the $0.62-\mu \mathrm{m}$ and the $0.87-\mu \mathrm{m}$ channels, respectively (solid with symbols). There are two curves of the latter kind, each corresponding to a different value of the surface reflectance. The size distribution is retrieved from the best fit of an aerosol model to the sky radiance for scattering angle $\Theta \leq 40^{\circ}$. The phase function is retrieved from the whole almucantar. Two extreme cases of measurements are shown (a) in desert transition zone in Sede Boker, Israel, with a strong influence from large dust particles and (b) in Prague, the Czech Republic, with a strong influence from sulfate particles. (c) and (d) The relative differences between the recalculated and the measured radiances (\%). Solid curves, inversion for $\Theta \leq 40^{\circ}$; dashed, for all values of $\Theta$. Thin curves for $\lambda=0.44 \mu \mathrm{m}$, thick for $\lambda=0.87 \mu \mathrm{m}$, and intermediate for $\lambda=0.62 \mu \mathrm{m}$. The derived size distributions are shown in Figure 2.

that collected the data much faster. As a result a second version of the procedure was applied, in which the sky radiances from each channel are used separately to derive the aerosol size distribution (dashed curves in Figure 2) and then averaged to obtain the final size distribution (solid curves with marks). The oscillations are much smaller on the individual size distributions and insignificant for the average size distribution. Note the differences in the derived size distributions for the different aerosol types:

1. The heavily polluted air in Prague during the summer has a strong accumulation mode (radius $<0.6 \mu \mathrm{m}$ ) which indicated the presence of particles generated in a gas to liquid conversion (e.g., sulfates).

2. The coarse particle mode (particle radius $1-4 \mu \mathrm{m}$ ) is most dominant in desert conditions (Sede Boker) during a dust storm (e.g., on February 6, 1991). In situ measurements during a dust storm in the vicinity of Sede Boker show very similar elevated concentrations of the volume distribution between $1 \mu \mathrm{m}$ and $5 \mu \mathrm{m}$ [Levin et al., 1980].

3. The size distribution retrieved from the data in 1992 indicates the presence of stratospheric sulfate aerosol located around a radius of $0.5 \mu \mathrm{m}$. In this radius range there are not many particles in the troposphere, thus generating a "window" through which the stratospheric particles can be observed.

In Figure 1 the recomputed sky radiance for the retrieved scattering phase function is also plotted. The fact that we were able to get a very good fit between the recomputed radiance and the measured radiance shows that the retrieved size distribution is able to explain the angular dependence of the sky radiance and, therefore, also the angular dependence of the single-scattering phase function.

\section{Sensitivity Study}

A sensitivity study was performed to test the accuracy of the inversion scheme and the effect of anticipated sources of errors on the retrieval of the aerosol size distribution. The results are shown in Figure 3. The inversion was performed for a single lognormal distribution (top two rows) and for two lognormal distributions with separate and overlapping modes (bottom row). The simulation of the sky radiance included the effects of polarization and used the vector code of Dave and Gazdag [1970] for the top two rows of Figure 3. Scalar code with no polarization was used for the bottom row. The size distribution was retrieved using the scalar code of Nakajima et al. [1983]. It is expected that the retrieved size distribution will be accurate for a radii range of $0.1 \mu \mathrm{m} \leq r \leq 8 \mu \mathrm{m}$ [Shiobara et al., 1991].

Size distributions retrieved from the simulated radiances, without noise in the data or errors in the retrieval procedure, result in high accuracy ot the retrieval in the range of $0.1 \mu \mathrm{m}$ $\leq r \leq 8 \mu \mathrm{m}$. In cases of a single aerosol mode with very low concentration of small or large particles, artificial particles of up to $4 \%$ of the maximum concentration were generated by the inversion process. The sensitivity to errors in the assumed refractive index, or in the measurement conditions (calibration, stray light, or errors in the measurements of the azimuth), an average error of $10 \%$ was detected for particles above $3-\mu \mathrm{m}$ radius. For particles under $0.1 \mu \mathrm{m}(0.05 \mu \mathrm{m} \leq r$ $\leq 0.1 \mu \mathrm{m}$ ) the retrieved size distribution diverges from the true distribution but is within a factor of 2 of the true density and therefore still useful. We tested the effect of several sources of errors: uncertainty in the refractive index of the real part $\Delta n_{r}=0.05$, uncertainty in the imaginary index of 

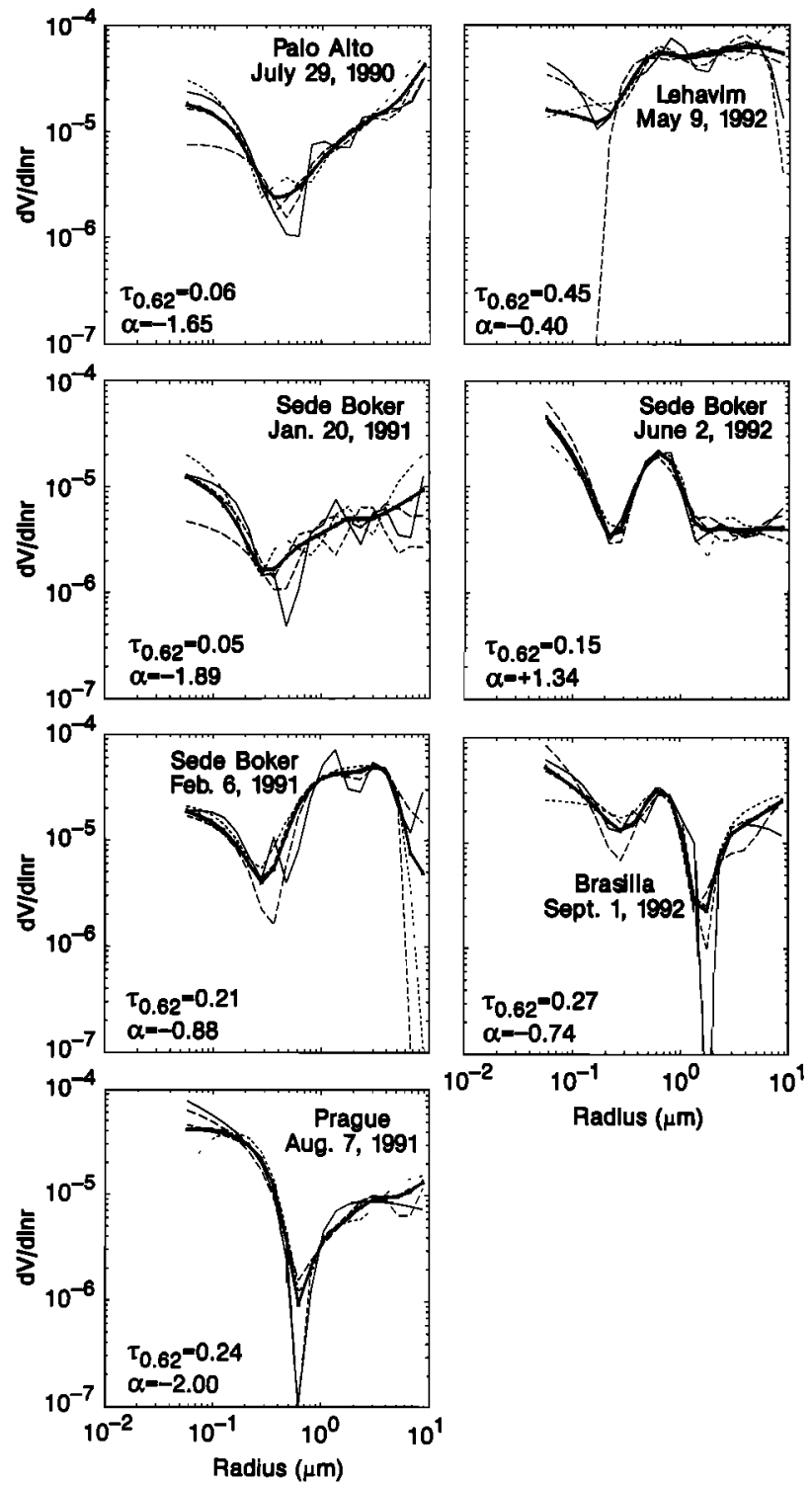

Figure 2. Examples of size distributions derived from the sky radiances. The dashed curves are the size distribution derived from the radiances in each channel separately (the shortest dashed curve for $0.44 \mu \mathrm{m}$ and the longest dashed for $0.87 \mu \mathrm{m}$ ). The thick solid curve gives the average of the three size distributions. The thin solid curve is the size distribution derived from the radiances in all the wavelengths simultaneously. This size distribution is more "noisy" due to calibration errors and due to variability of the sky conditions. The location of the measurement, the date, value of the optical thickness, $\tau$ at $0.62 \mu \mathrm{m}$, and the Angström exponent, $\alpha=\Delta \ln \tau / \Delta \ln \lambda$, derived from $\tau(\lambda)$ are given for each figure.

$\Delta n_{i}=0.0015$, uncertainty in the ground reflectance of $\Delta \rho=$ 0.1 , error in the measured scattering angle by $0.5^{\circ}$, calibration errors of $10 \%$ and $15 \%$ in various channels, and the effect of stray light ( $3 \%$ at $2^{\circ}$ decreasing to $0 \%$ at $4^{\circ}$ ). All these errors represent the maximum anticipated uncertainty in each parameter. The only significant errors occurred due to an error in the scattering angle, which affected the concentration of the coarse particles by $40 \%$. Therefore special care was given to precise measurements of the scattering angle, and mainly for small scattering angles, where the sky radiance is very sensitive to the concentration of the large particles. We estimate that the average error in a single measurement of the scattering angle for viewing close to the Sun is $\pm 0.5^{\circ}$. This error combines error in the location of the Sun relative to the field of view and error in the viewing position. Since each size distribution is the result of analysis of six aureole measurements (three wavelengths and the two sides of the Sun), therefore the average error in the measured scattering angle is $\sim 0.2^{\circ}$.

The main errors in retrieving the single-scattering phase function from the wide angle radiances are from the assumed value of the surface reflectance and from spatial nonhomogeneity of the aerosol layer. The plots of the recomputed radiances in Figure 1 show that the measured radiance can be very accurately reconstructed by the radiative transfer inversion except for fluctuations in the measured radiances due to nonuniformity of the sky conditions. The error in the derived phase function for a given uncertainty in the surface reflectance depends on the ratio of molecular scattering to aerosol scattering. For small aerosol optical thicknesses the contribution to the sky radiance and to the error from backscattering by molecules of light reflected from the surface is larger. To show the effect of the error in the assumed surface reflectance on the derived phase function, the phase functions are derived from the measured sky radiance always using two values of the surface reflectance. An uncertainty of $\Delta \rho=0.1$ was used for $\lambda=0.62 \mu \mathrm{m}$ and $\Delta \rho$ $=0.2$ for $\lambda=0.87 \mu \mathrm{m}$. In Figure 4 the effect of the various error sources on the derived phase function is shown for lognormal size distributions with small particles $\left(r_{g}=0.05\right)$ and large particles $\left(r_{g}=0.5\right)$. The main source of error is due to uncertainty in the surface reflectance $(\Delta \rho=0.2-$ the dashed curve for $r_{g}=0.5$ ) which for the purpose of demonstration is twice the error assumed in the analysis of the data. Wang and Gordon [1993] reported the results of a sensitivity study of the derivation of the scattering phase function and single-scattering albedo from almucantar radiances. The sensitivity of the phase function to sources of errors (error in the optical thickness, calibration, noise) was small, similar to the present results.

\section{Detailed Results}

In this section we discuss the detailed results of the retrieved size distributions and the single-scattering phase function. In some cases, parallel information on the aerosol particles can be derived both from the solar attenuation measurements and from the sky brightness measurements. We shall use these opportunities to compare and test the aerosol properties derived from these two measurements.

\section{Aerosol Optical Thickness From Solar and Sky Measurements}

The analysis of the size distribution is essentially independent of the measured optical thickness. Therefore as a check of the quality of measurements, calibrations, and the inversion procedure, the aerosol optical thickness derived from the solar measurements $\left(\tau_{\text {sun }}\right)$ is compared with optical thickness computed as an integral on the retrieved size distributions from the sky brightness $\left(\tau_{\text {sky }}\right)$. In Figure 5a, scatter diagrams between $\tau_{\text {sun }}$ and $\tau_{\text {sky }}$ are plotted for three wavelengths. Different symbols are used for the 1990-1991 

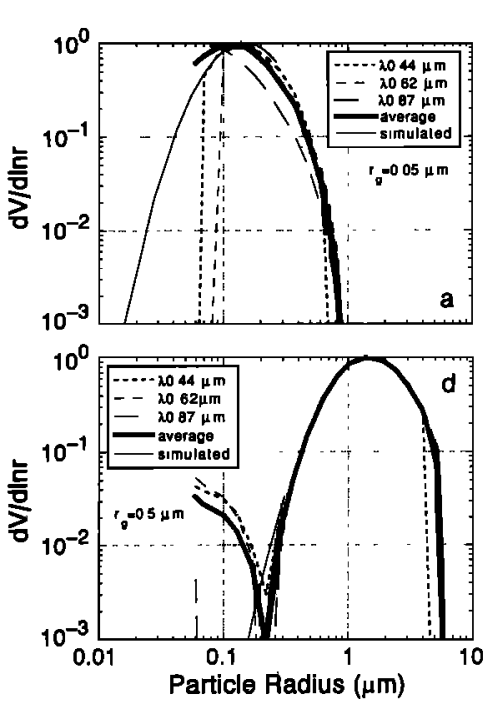
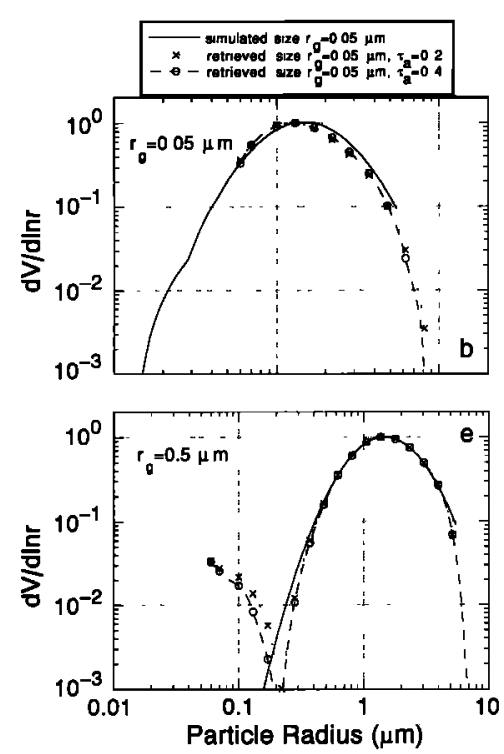
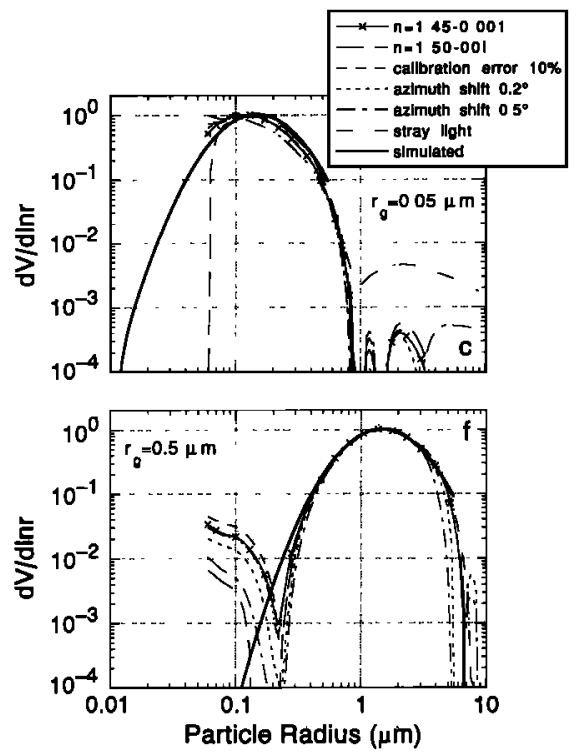

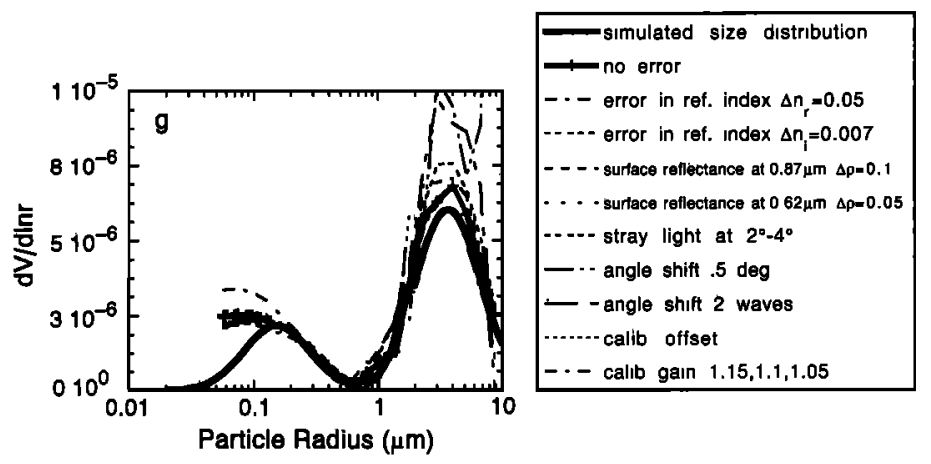

Figure 3. Result of a sensitivity study of the effect of uncertainties in the measurements and the inversion procedure on the retrieved size distribution. The simulation was done using the radiative code of Dave and Gazdag [1970] for polarized (top two rows) and unpolarized light (bottom row) and the inversion using the scalar code of Nakajima et al. [1983]. The simulation was performed for a single lognormal mode with small (top row, $r_{g}=0.05 \mu \mathrm{m}$ ) and large particles (middle row, $r_{g}=0.5 \mu \mathrm{m}$ ) and for two lognormal modes (bottom row). (a) and (d) The simulated size distribution (thin curves), the retrieved distributions from single channels (dashed), and the average of these distributions (thick). (b) and (e) The simulated size distribution (thin), an the retrieved one, averaged on the three channels for $\tau_{a}=0.2$ and 0.4. (c) and (f) Sensitivity to errors in the refractive index (1.50 instead of 1.45) calibration, measurement of the azimuth and stray light. The simulated size distribution is given here by thick solid curves. (g) The simulated size distribution (thick) for a bilognormal size distribution. Sensitivity to refractive index (dashed), errors in the scattering angle of $0.5^{\circ}$ (dashed-three dotted), and calibration errors (short dashed).

data, before the Mount Pinatubo eruption, and for 1992 after the eruption ( $o$ and $x$, respectively). The correlation coefficient between $\tau_{\text {sun }}$ and $\tau_{\text {sky }}$ varies between 0.92 and 0.98 . Systematic variation between the two optical thicknesses can result from an error in the solar calibration, or an error in the sky calibration. The first would cause a shift in the intercept of the least square fit, while the second would affect the slope of the fit. For the shortest wavelength $(0.44$ $\mu \mathrm{m})$ a shift of $0.03 \pm 0.01$ for the two data sets indicates a possible inaccuracy of 0.03 in the Sun calibration, while the slope of the least squares fit is very close to one: $1.01 \pm 0.02$. Shifts of 0.01 to 0.03 are also found in the other two wavelengths, with slopes between 0.83 and 0.93 . Such calibration inaccuracies are expected, since the accuracy of the calibration itself is with errors of $\mathbf{\pm 0 . 0 2}$ for the Sun calibration and $\pm 10 \%$ for the sky calibration. Variation in the instrument response through this period of time and uncertainty in the refractive index can also account for part of the error.

\section{Relation Between the Volume Distribution and the Ångström Exponent}

Spectral dependence of the aerosol optical thickness expressed by the Ångström exponent

$$
\alpha=\frac{\Delta \ln \tau_{a}}{\Delta \ln \lambda}
$$

is directly related to a power law size distribution [Junge, 1963; Kaufman, 1989]: 


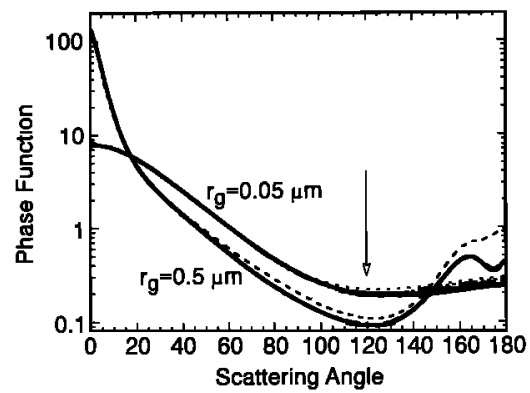

Figure 4. Scattering phase functions for lognormal size distributions of small $\left(r_{g}=0.05 \mu \mathrm{m}\right)$ and large $\left(r_{g}=0.5\right.$ $\mu \mathrm{m})$ particles, showing the variation in the phase function at scattering angle of $120^{\circ}$. Dashed curves show the deviation due to errors in refractive index, calibration, stray light, and measurements of the scattering angle. The error in the scattering angle, shown for $r_{g}=0.5 \mu \mathrm{m}$ (short dashed) is the largest error. Here the error was computed for $\Delta \rho=0.1$, which is twice as large as the uncertainty used in the inversion.

$$
\alpha=\frac{\Delta \ln \tau_{a}}{\Delta \ln \lambda} \Rightarrow \frac{d N}{d \ln r}=C r^{(\alpha-2)}
$$

where $N$ is the particle number density and $r$ is the particle radius. From the sky measurements we derive the particle volume distribution, which is related to the particle size distribution

$$
\frac{d V}{d \ln r}=4 \pi r^{3} \frac{d N}{d \ln r}=C_{1} r^{\alpha+1}
$$

Even though the volume distributions derived from the sky radiances, e.g., Figure 2, do not resemble a power law, it is interesting to check the relationship of the ratio of the two size distribution modes to the Ångström exponent $\alpha ; \alpha$ is easier to measure and can be measured more frequently. Note that the optical thickness is sensitive to particle sizes in the range of $0.06 \mu \mathrm{m}$ to $2.5 \mu \mathrm{m}$ [King et al., 1978], which is narrower than the range of sensitivity of the almucantar measurements. In Figure 6 a scatter diagram is shown between the ratio of the concentration of small particles $\Delta V_{1}$ $=(0.057 \mu \mathrm{m}-0.21 \mu \mathrm{m})$ to the concentration of large particles $\Delta V_{2}=(1.8 \mu \mathrm{m}-4.0 \mu \mathrm{m})$ and the value of $\alpha$. The scatter diagram is for data taken before and after the enhancement of the stratospheric aerosol. The relationship between $\Delta V_{1}$ / $\Delta V_{2}$ and $\alpha$ can be approximated by an exponential function for the 1990-1991 data (straight line in Figure 6a), while there is no clear relation for 1992 due to the dominance of the intermediate particle size (radius around $0.5 \mu \mathrm{m}$ ) of the stratospheric aerosol. The exponential dependence between $\Delta V_{1} / \Delta V_{2}$ and $\alpha$ observed for 1990-1991 can be explained from (1) and (3) for a power-law size distribution

$\frac{\Delta V_{1}}{\Delta V_{2}} \approx \frac{\Delta r_{1}}{\Delta r_{2}}\left(\frac{r_{1}}{r_{2}}\right)^{\alpha}$ or $\ln \left(\frac{\Delta V_{1}}{\Delta V_{2}}\right) \approx C_{0}+\alpha \ln \left(r_{1} / r_{2}\right)$

Detailed information on the distributions of the aerosol particles in several particle size ranges are shown in Figure 7. In this figure the fraction of the volume of particles is shown in each particle size range as a function of $\alpha$. The results are shown separately for the desert transition zone

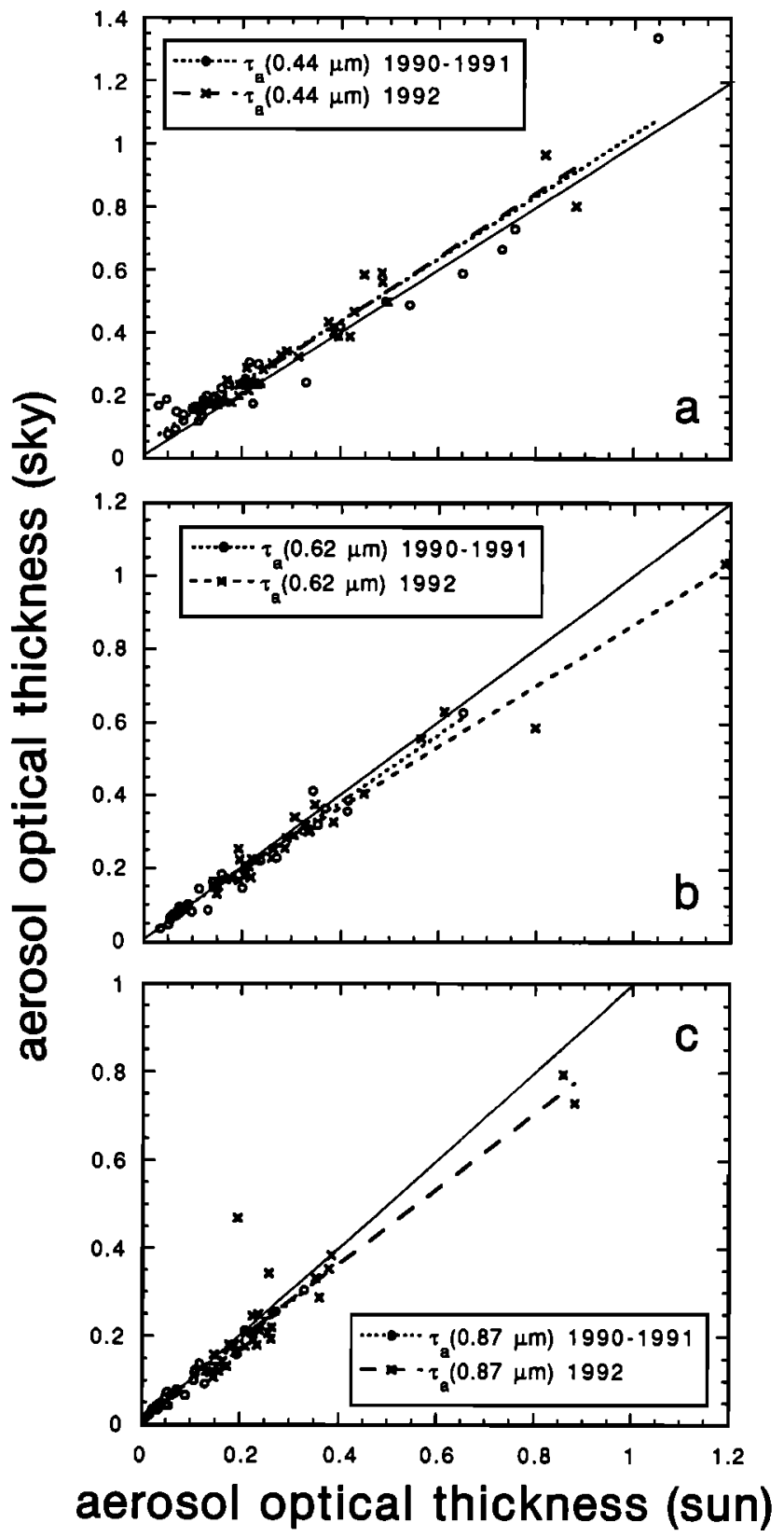

Figure 5. A scatter diagram between $\tau_{\text {sun }}$, the aerosol optical thickness derived from the solar measurements, and $\tau_{\text {sky }}$, the optical thickness computed from the retrieved size distributions from the sky data. Open circles, data for the 1990-1991 period, before the Pinatubo eruption; (x), data for 1992 after the eruption. The correlation coefficient between $\tau_{\text {sun }}$ and $\tau_{\text {sky }}$ varies between 0.92 and 0.98 . The least squares fit line is shifted from the origin by $0.01-0.03$, indicating a possible inaccuracy in $\tau_{\text {sun }}$. The slope of the line is very close to a unit: $1.01 \pm 0.02$ for $\lambda=0.44 \mu \mathrm{m}$ and 0.83 and 0.93 for the other two wavelengths $(0.62$ and $0.87 \mu \mathrm{m})$. Difference from 1.0 indicates a possible error in the sky calibration (see text).

and for Europe and California. The aerosol optical thickness is smaller in California (taken within $30 \mathrm{~km}$ off the coast from San Diego to San Francisco), where it is dominated by maritime/rural aerosol with contribution from urban pollu- 
tion, than in Europe. In Europe the stable meteorological conditions and high humidity causes a high rate of sulfate aerosol production and accumulation. Only data collected in 1990-1991 before the injection of the stratospheric aerosol are plotted. The figure shows that the increase in $\alpha$ is associated in both cases, as expected, with a reduction in the concentration of the small particles. The aerosol optical thickness is also plotted in the same figure for comparison. It is interesting to note that for the desert transition zone (Figure 7b) an increase in $\alpha$ is associated with an increase in the optical thickness. In this region, the advection of large dust particles increases the optical thickness and increases the value of $\alpha$. The trend is opposite in the industrial zone (Europe and California, Figure 7a) where the increase of aerosol optical thickness is associated with a decrease in the value of $\alpha$ due to an increase in the concentration of the small sulfate particles.

\section{Stratospheric Aerosol From the Mount Pinatubo Eruption}

The collection of the almucantar measurements started in May 1990 and continued to the end of 1992 . The purpose of this long though sporadic data collection was to generate
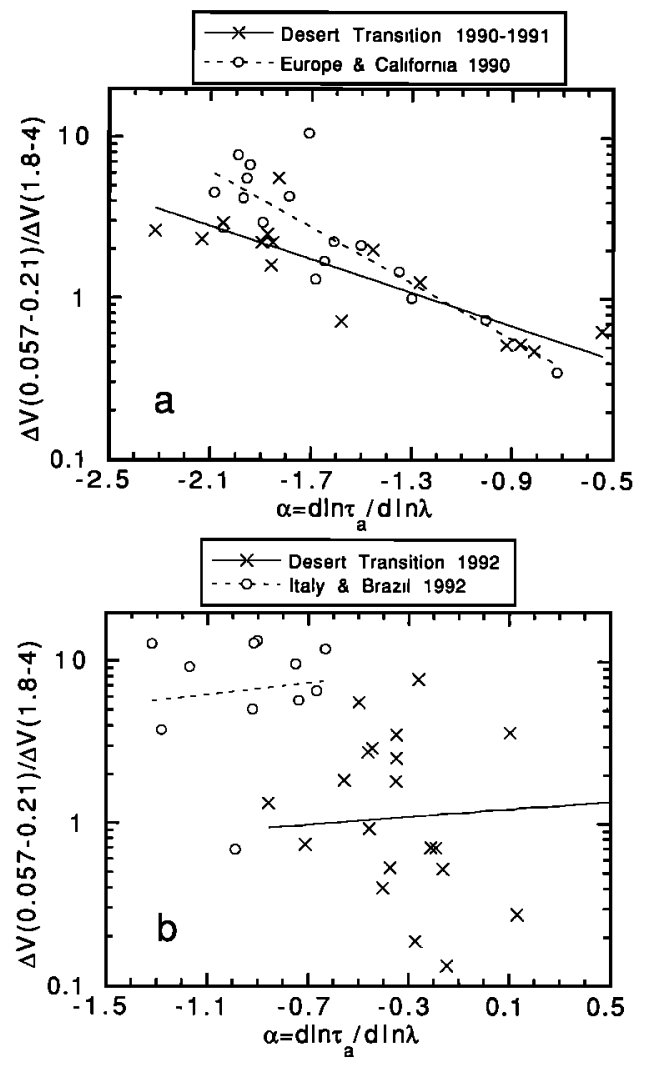

Figure 6. Scatter diagrams between the ratio of the concentration of small particles (radius range: $0.057-0.21 \mu \mathrm{m}$ ) to the concentration of large particles (radius range: $1.8-4.0$ $\mu \mathrm{m})$ and the exponent $\alpha$ that describes the spectral dependence of the optical thickness. (a) Data for 1990-1991 before the injection of the stratospheric aerosol; (b) data for 1992 after the injection of the stratospheric aerosol. (x) Data from the desert transition zone in Israel; open circles, data from other areas as indicated in each figure. Data from Europe were heavily affected by sulfate particles and the data from Brazil by smoke.

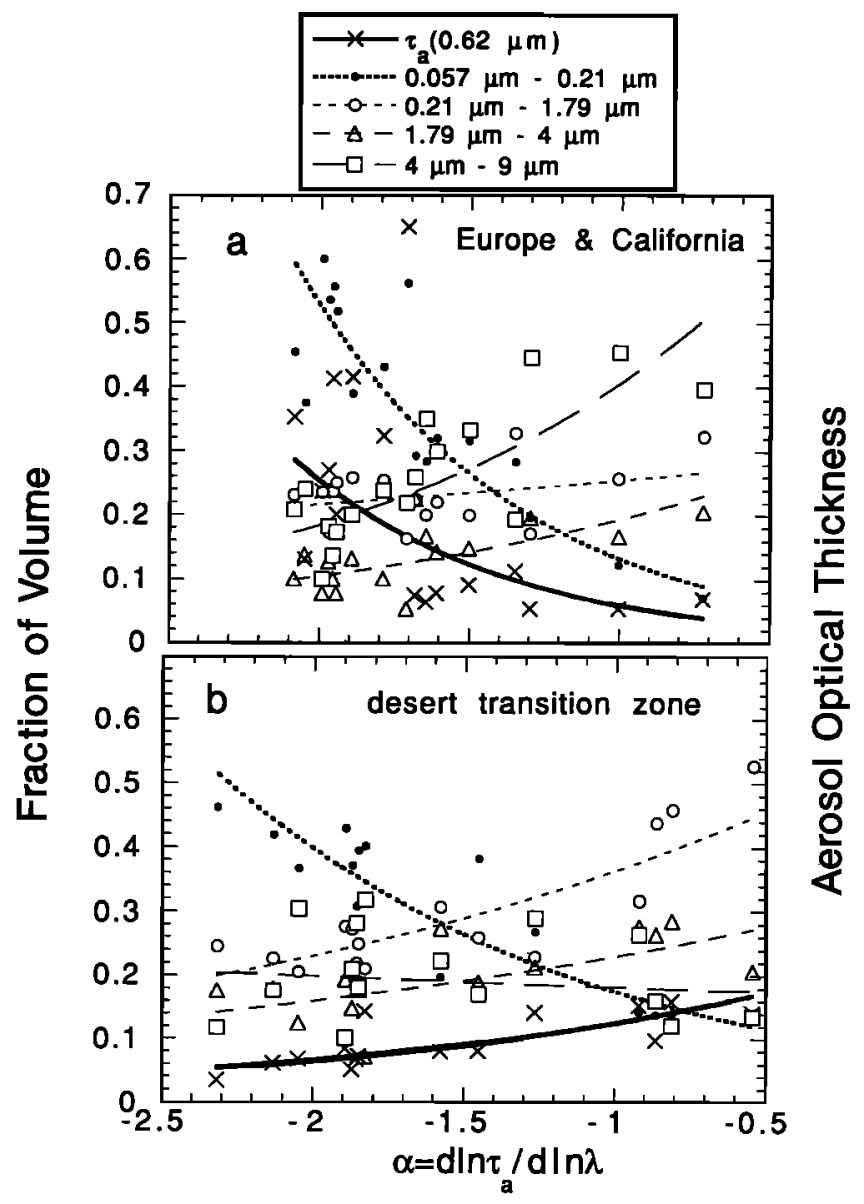

Figure 7. Fraction of the volume of particles in each size range, as indicated in the figures, as a function of the spectral dependence of the optical thickness, $\alpha$. The aerosol optical thickness $\tau_{a}$ is also plotted ( $\mathrm{x}$ and solid lines). (a) Result for Europe and California in 1990. (b) Results for the desert transition zone in 1990-1991.

significant statistics of the aerosol physical and optical properties for various aerosol types. The eruption of the Mount Pinatubo in June 1991 changed the characteristics of the data set. As a result we were forced to use only the 1990-1991 data in the analysis of the previous section, leaving the 1992 data primarily to analyze the properties of the stratospheric aerosol. This is similar to the measurements of Shiobara et al. [1991] which were influenced, in a similar way, by the eruption of El Chichon.

The effect of the stratospheric aerosol on the measured size distribution was shown in the individual examples of Figure 2. In Figure 8, individual size distributions are magnified around the stratospheric aerosol size for measurements at three locations: Sede Boker, Israel; Lake Maggore, Italy; and Brasilia, Brazil. The size distribution around the $0.5-\mu \mathrm{m}$ stratospheric aerosol particles is much more stable than in other size ranges. This is expected since the measurements were taken at least 6 months after the eruption, which is long enough for most $\mathrm{SO}_{2}$ to convert to sulfate particles [Turco et al., 1983], for coagulation processes to take place [Thomason, 1992] and for the aerosol layer to spread across longitudinal lines and homogenize [Stowe et al., 1992]. The derived size of the stratospheric aerosol 

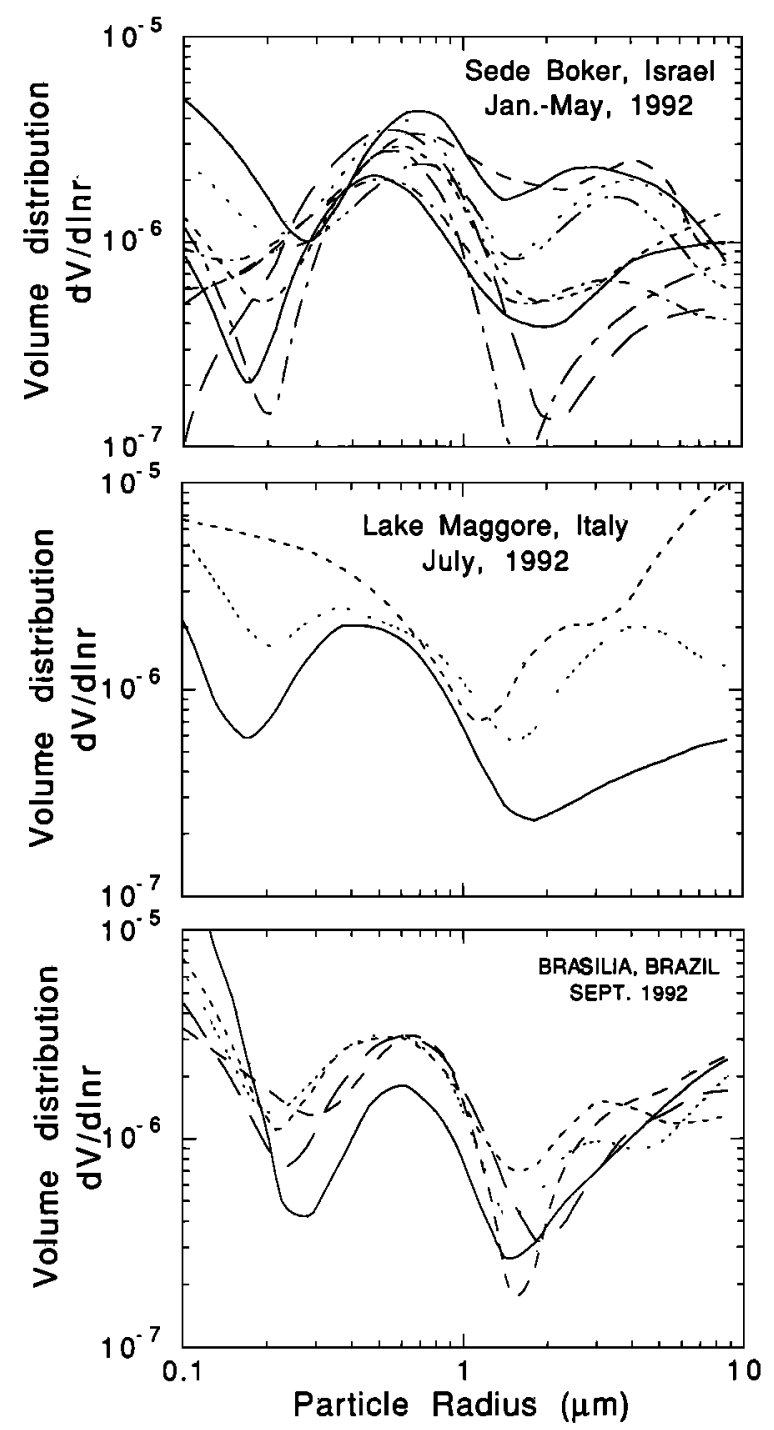

Figure 8. Individual size distributions derived from the almucantar measurements in Sede Boker, Israel $\left(30.5^{\circ} \mathrm{N}\right.$, $\left.34.7^{\circ} \mathrm{E}\right)$; Lake Maggore, Italy $\left(45.5^{\circ} \mathrm{N}, 8^{\circ} \mathrm{E}\right)$; and Brasilia, Brazil $\left(16.1^{\circ} \mathrm{S}, 44.3^{\circ} \mathrm{W}\right)$. The size distribution around the $0.5-\mu \mathrm{m}$ radius shows the presence of the stratospheric aerosol.

particles is very similar to the results of Shiobara et al. [1991] and to analysis of aircraft measurements by King et al. [1984] for the El Chichon aerosol.

Averaging the different size spectra prior to and after the Pinatubo eruption for the different ecosystems results in smooth size distributions that show clearly the presence of the stratospheric aerosol. These average size distributions are plotted in Figure 9. For both the desert transition zone data and the data from Europe and California the average size distribution of the small and large particles is very similar for the 1990-1991 and the corresponding 1992 data sets. The main difference between the data sets is the stratospheric aerosol that is located in a range of particle sizes that corresponds to a "hole" in the tropospheric aerosol size distribution and therefore is clearly seen.

From individual size distributions for the lowest total optical thickness, indicating the lowest concentration of tropospheric aerosol, it is possible to compute the detailed size distribution of the stratospheric aerosol. These size distributions are fitted with lognormal functions:

$$
\frac{d V}{d \ln r}=N_{0} e^{-\left(\ln r / r_{m}\right)^{2} /\left(2 \sigma^{2}\right)}
$$

where $r_{m}$ is the volume mean particle radius and $\sigma$ is the standard deviation of the distribution. $N_{0}$ is the particle volume density in units of $\mathrm{cm}^{3} / \mathrm{cm}^{2}$. The results for $N_{0}, a$, and $\sigma$ are plotted in Figure 10. During the period of 6-12 months after the eruption of Pinatubo and beyond, the values of these parameters of the lognormal distribution did not change significantly with time. Similar stability of the stratospheric aerosol optical thickness was determined from pyrheliometer measurements from Mauna Loa in Hawaii [Duton and Christy, 1992]. Sunphotometer measurements from Mauna Loa show stability of the optical thickness and its wavelength dependence (E. G. Dutton, personal communication, 1992) during this period of time. Shiobara et al. [1991] found from similar measurements that the concentration of stratospheric aerosol from El Chichon increased during the first 6 months and was stable during the next 6 months before decreasing afterward. This is probably due to a temporal equilibrium between aerosol formation from the gaseous form and gravitational deposition of the aerosol particles.

\section{Single-Scattering Phase Function}

A comparison between $\boldsymbol{P}_{s}$, phase function computed from the derived size distribution assuming homogeneous spher-
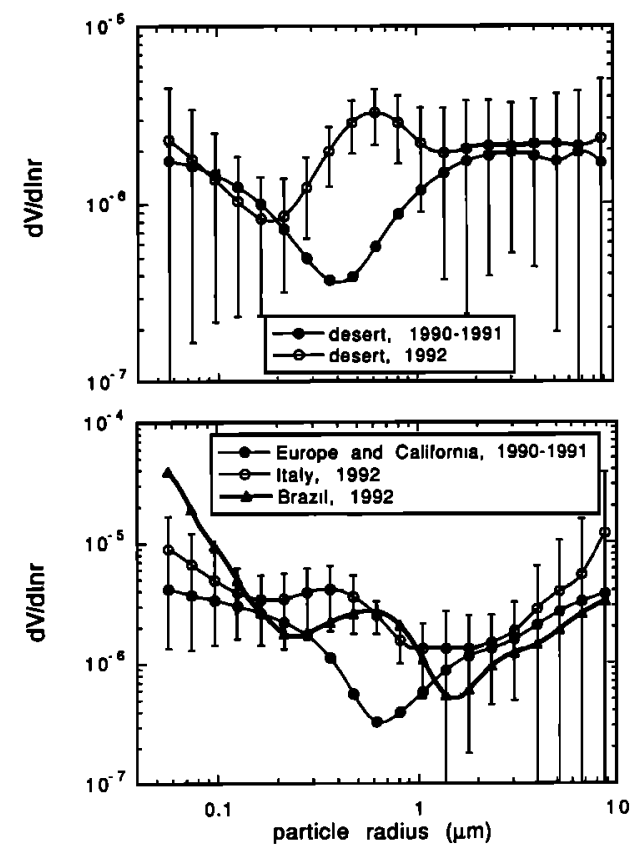

Figure 9. Comparisons between the average size distribution prior and after the Mount Pinatubo eruption. The average size distributions are shown for the desert transition zone, for Europe/California, and for Brazil. The standard deviations in two of the data sets are shown by the vertical bars. The average size distribution of the small and large particles is very similar for the 1990-1991 data sets and the corresponding 1992 data sets. The 1992 data show the presence of the stratospheric aerosol around $0.5-\mu \mathrm{m}$ radius. 
ical particles, and $\boldsymbol{P}_{a}$, the actual phase function derived from the sky radiance at large scattering angles, can show the effects of particle nonsphericity and nonhomogeneity on the scattering phase function. A comparison between $P_{s}$ and $P_{a}$ is plotted in Figure 11 as a function of the Ångström exponent $\alpha\left(\alpha=\Delta \tau_{a} / \Delta \ln \lambda\right)$. The left column is for data measured in the desert transition zone in Israel and the right column is for the rest of the data with strong contribution from sulfate aerosol. The data are separated into prePinatubo (1990-1991) and post-Pinatubo (1992) data. Because of the large aerosol particles present in the stratosphere from the volcanic eruption the value of $\alpha$ is much larger for 1992, separating it from the 1990 to 1991 data. For comparison, also the optical thickness is plotted in the figure as a function of $\alpha$. Due to a large noise in individual phase functions, of $10-30 \%$, instead of showing the individual values of the phase function, the averages are displayed for subgroups of 4-7 measurements, in order of increasing optical thickness.

In 1992 the stratospheric aerosol dominates the spectral dependence of the optical thickness, $\alpha$. The large particle size of the stratospheric aerosol corresponds to values of $\alpha$ close to zero, and therefore reduction of the tropospheric aerosol optical thickness increases the value of $\alpha$. The stratospheric aerosol is dominated by liquid sulfuric acid, therefore it is expected that the majority of the particles are spherical and homogeneous, resulting in a good agreement between $\boldsymbol{P}_{s}$ and $\boldsymbol{P}_{a}$. The present measurement, shown in Figure 11, confirms this hypothesis. In other cases the difference between $P_{s}$ and $P_{a}$ is $0-50 \%$. Note that the difference between the small and large open symbols represent the error in the derived value of $\boldsymbol{P}_{a}$ due to uncertainty in the surface reflectance. This uncertainty causes large errors for small aerosol optical thicknesses. We expected the difference between $\boldsymbol{P}_{s}$ and $\boldsymbol{P}_{a}$ to correlate with the value of $\alpha$. High $\alpha$ is generated by large particles that are expected to be nonspherical (except for the stratospheric aerosol). But no such clear relationship was observed.

In addition to the two phase functions $P_{s}$ and $P_{a}$ a third phase function, $P_{\alpha}$, is plotted in Figure 11. This phase

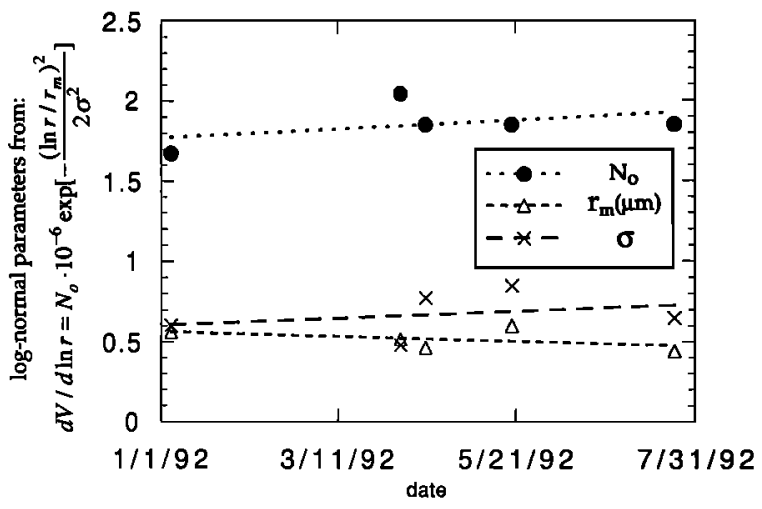

Figure 10. Lognormal parameters of the stratospheric aerosol size distributions that correspond to five measurements with the lowest total optical thicknesses during 1992. The lognormal function is defined by $(d V / d \ln r)=N_{0} e^{-\left(\ln r / r_{m}\right)^{2} /\left(2 \sigma^{2}\right)}$, where $r_{m}$ is the median particle size of the volume distribution and $\sigma$ is the width of the distribution. $N_{0}$ is the particle volume density $\left(\mathrm{cm}^{3} / \mathrm{cm}^{2}\right)$.
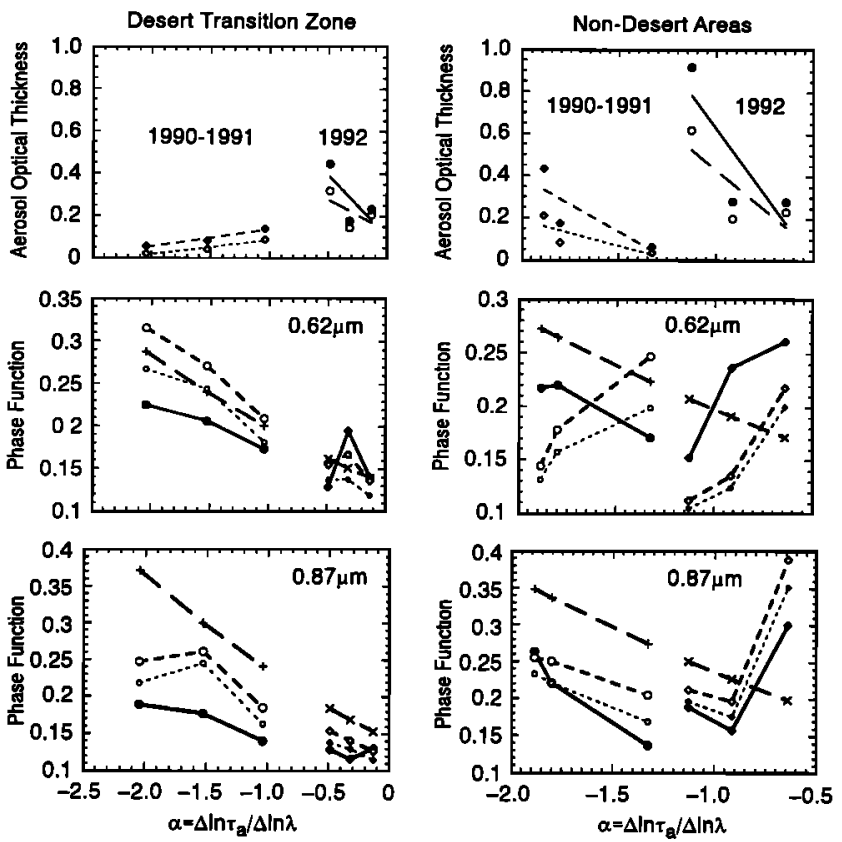

Figure 11. The aerosol optical thickness and the scattering phase function (for scattering angle of $120^{\circ}$ ) as a function of the Ångström exponent $\alpha=\Delta \tau_{a} / \Delta \ln \lambda$. The left column is for data measured in the desert transition zone in Israel and the right column for the rest of the data with strong influence of anthropogenic sulfate aerosol. The data are separated into pre-Pinatubo data (1990-1991) and post-Pinatubo data (1992). The first row of figures shows the aerosol optical thicknesses for $0.62 \mu \mathrm{m}$ (solid symbol) and for $0.87 \mu \mathrm{m}$ (open symbol). The second and third rows of figures are for the phase function for 0.62 and $0.87 \mu \mathrm{m}$, respectively. Solid symbols are for the scattering phase function computed from the derived size distributions assuming spherical homogeneous particles. The open symbols (large and small) are for the actual phase function derived from the sky radiance at large scattering angles for low and high estimates of the surface reflectance (respectively). For comparison also a phase function computed assuming a power law size distribution for the measured value of $\alpha$ is also shown (pluses).

function is computed assuming a power law size distribution with the measured Ångström exponent $\alpha$. For $\lambda=0.62 \mu \mathrm{m}$ the power law phase function, $P_{\alpha}$, has similar values to the other phase functions. This is mainly true for the desert conditions. At $\lambda=0.87 \mu \mathrm{m}$, the power law phase function overestimates the actual phase function by $30-50 \%$.

It is concluded that the effect of nonsphericity and nonhomogeneity of the particles on the phase function is small in the present data set $(20 \% \pm 15 \%)$, in contrast with a threefold effect suggested by Koepke and Hess [1988] and a difference of $25-80 \%$ for yellow dust shown by Nakajima et al. [1989]. Part of this small difference between $\boldsymbol{P}_{s}$ and $\boldsymbol{P}_{a}$ may be the result of uncertainty in the surface reflectance and part in real difference in the phase functions. No dependence was found of the difference $P_{s}-P_{a}$ on $\alpha$ (or on the particle size). While $P_{s}$ tends, on average, to underestimate the phase function, a phase function based on a power law size distribution, $P_{\alpha}$, predicts reasonably well the phase function for $0.62 \mu \mathrm{m}$ but overestimates it for the $0.87-\mu \mathrm{m}$ channel. In a previous paper [Kaufman, 1993], predictions of the atmospheric path radiance using a power law assumption 


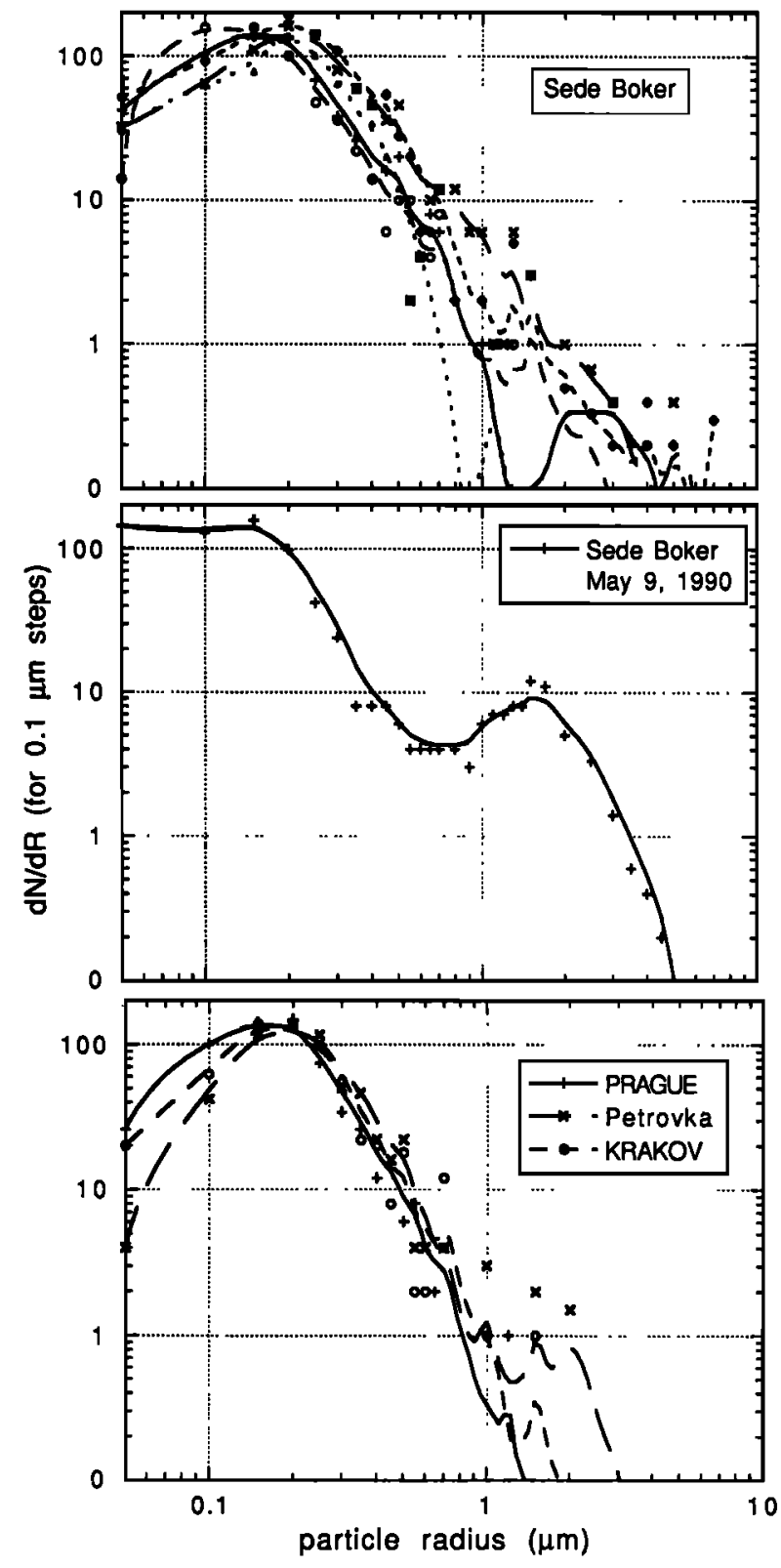

Figure 12. Size distributions obtained from nine analyses of filter samples. Top figure is for five background aerosol samples from a desert transition zone in Sede Boker, Israel. The middle figure is for a moderate dust event May 9, 1990, in Sede Boker, showing the enhancement of large particles. The bottom figure is for three samples in Eastern Europe in July 1991. Total number of particles counted per radius range of $\Delta r=0.1 \mu \mathrm{m}$ is plotted as a function of the particle radius. The lines in the figures shows a smooth curve passing through the points.

were found to be in agreement with measurements for 0.63 $\mu \mathrm{m}$ but were underestimating the measurements for 0.82 $\mu \mathrm{m}$. This spectral difference in the applicability of the power law assumption in the computation of the scattering phase function may result from the larger influence of the coarse particle mode on the phase function at larger spectral wavelengths.

\section{Individual Particle Analysis}

During the almucantar measurements on May 9, 1990, aerosol particles were collected directly on three carboncovered electron microscope stages of a Casella cascade impactor [May, 1945]. They were used to study the morphology and chemistry of individual particles with the aid of a
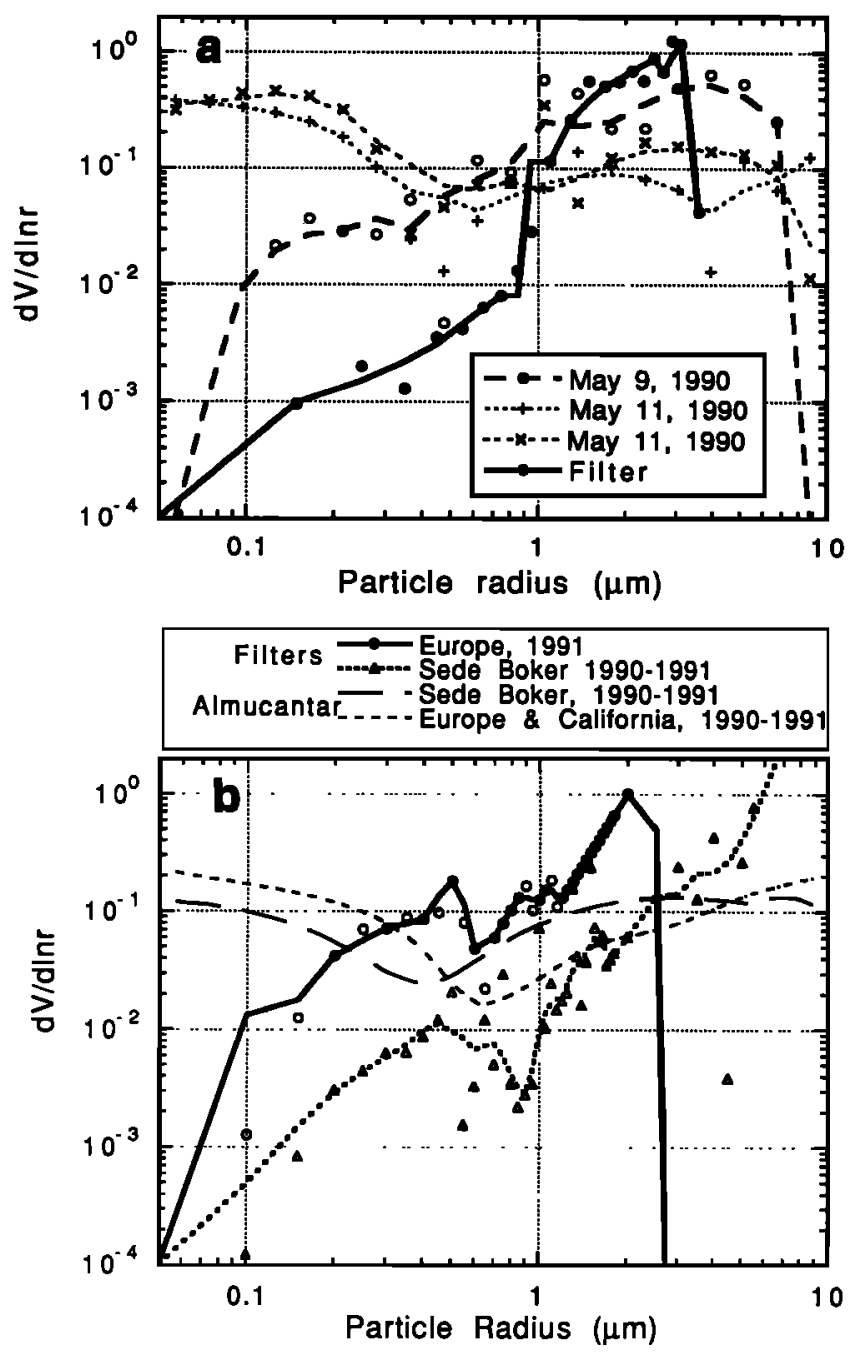

Figure 13. Comparison between the aerosol size distributions derived from almucantar data collected prior to the Mount Pinatubo eruption and size distribution derived from analysis of particles collected on filters. (a) Comparison between almucantar spectra for May 11, 1990, taken 1.5 hours apart for background desert transition aerosol $\left(\tau_{a}=\right.$ 0.16 at $0.52 \mu \mathrm{m}$ and $\alpha=-1.8$ ) and for a moderate dust storm at May 9, $1990\left(\tau_{a}=0.33\right.$ at $0.52 \mu \mathrm{m}$ and $\left.\alpha=-0.3\right)$. For May 9, 1990, also the size distribution derived from analysis of a cascade impactor is shown. The cascade impactor was exposed to the dust from an aircraft, during the aircraft climbing from $1300 \mathrm{~m}$ above sea level to $1700 \mathrm{~m}$. (b) Comparison between the average size distribution from almucantar analysis and filter sampling $1 \mathrm{~m}$ above the ground. Data are given for Europe (solid curve and circles for the filter data and long-dashed for the almucantar data) and for the desert transition zone in Israel (dotted curve and triangles for the filter data and short dashed for the almucantar data). The filter data include six samples in the desert transition zone and four in Eastern Europe. 

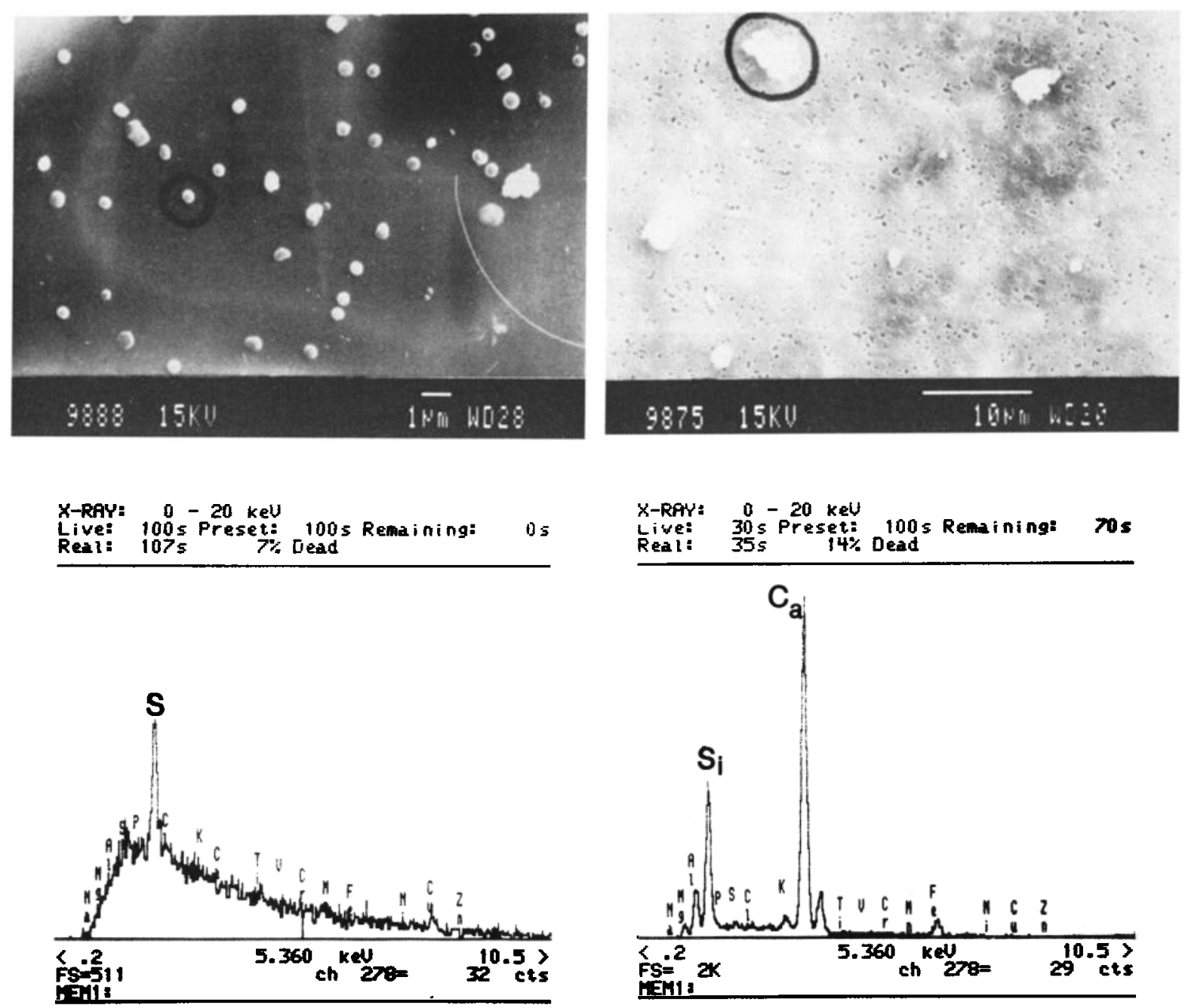

Figure 14. Examples of scanning electron microscope data of dust collected in Sede Boker, Israel, from an aircraft on May 9, 1990. On the left, with a scale of $1 \mu \mathrm{m}$, most particles are of submicron size, with large concentrations of sulfates (bottom left). On the right, with a scale of $10 \mu \mathrm{m}$, dust particles are observed, with large concentrations of calcium and silicon. The sulfate particles are spheroids, while the dust particles have an irregular shape. The sulfate (left) and dust (right) particles that are being analyzed are indicated by a circle.

transmission electron microscope (TEM) and a scanning electron microscope (SEM) equipped with an $\mathrm{X}$ ray energy analyzer. One screen was analyzed in the TEM for particle shape and the second was studied in the SEM for the elemental content of the particles. In other instances, particles were collected on polycarbonate membrane filters with a $0.8-\mu \mathrm{m}$ pore for $30-60 \mathrm{~min}$. Figure 12 shows the size distributions obtained from nine analyses of filter samples. Top figure is for five background aerosol samples from a desert transition zone in Sede Boker, Israel, collected between $1 \mathrm{~m}$ and $90 \mathrm{~m}$ above the ground (from a tower). The spectra are very similar one to another. The middle figure is for a moderate dust event May 9, 1990, in Sede Boker, collected with a cascade impactor from an aircraft during its ascent from $1300 \mathrm{~m}$ above sea level to $1700 \mathrm{~m}$. This sample shows the enhancement of large particles above the background. This size distribution was measured during a field experiment in May 1990 during a moderate dust storm that increased the aerosol optical thickness from an average of 0.10 in other days (see Table 1) to 0.32 at $\lambda=0.62 \mu \mathrm{m}$ and increased the value of $\alpha$ from -1.5 to -0.3 . The cascade impactor was pumped with a constant airflow and was exposed to the dust from the light aircraft. The size distribution was obtained from the four stages of cascades by counting particles of a given size range. The bottom part of Figure 12 is for three samples in Eastern Europe in July 1991, showing that the large particles present in the desert are missing in this environment.

The size distribution obtained from the filter data during the moderate dust storm on May 9, 1990, are converted in Figure 13a to volume distributions and compared with results of almucantar analysis. For comparison the size spectra from almucantar analysis on a background day, May 11 , are also plotted. The sampled spectra were normalized to a unit particle volume. There is some similarity between the in situ (filter) size distributions and the almucantar measurements. Both show a strong increase in the concentration of the micron size particles on May 9, above that on May 11. The submicron particle mode is much smaller in the analysis of the cascade impactor from the analysis of the almucantar. 


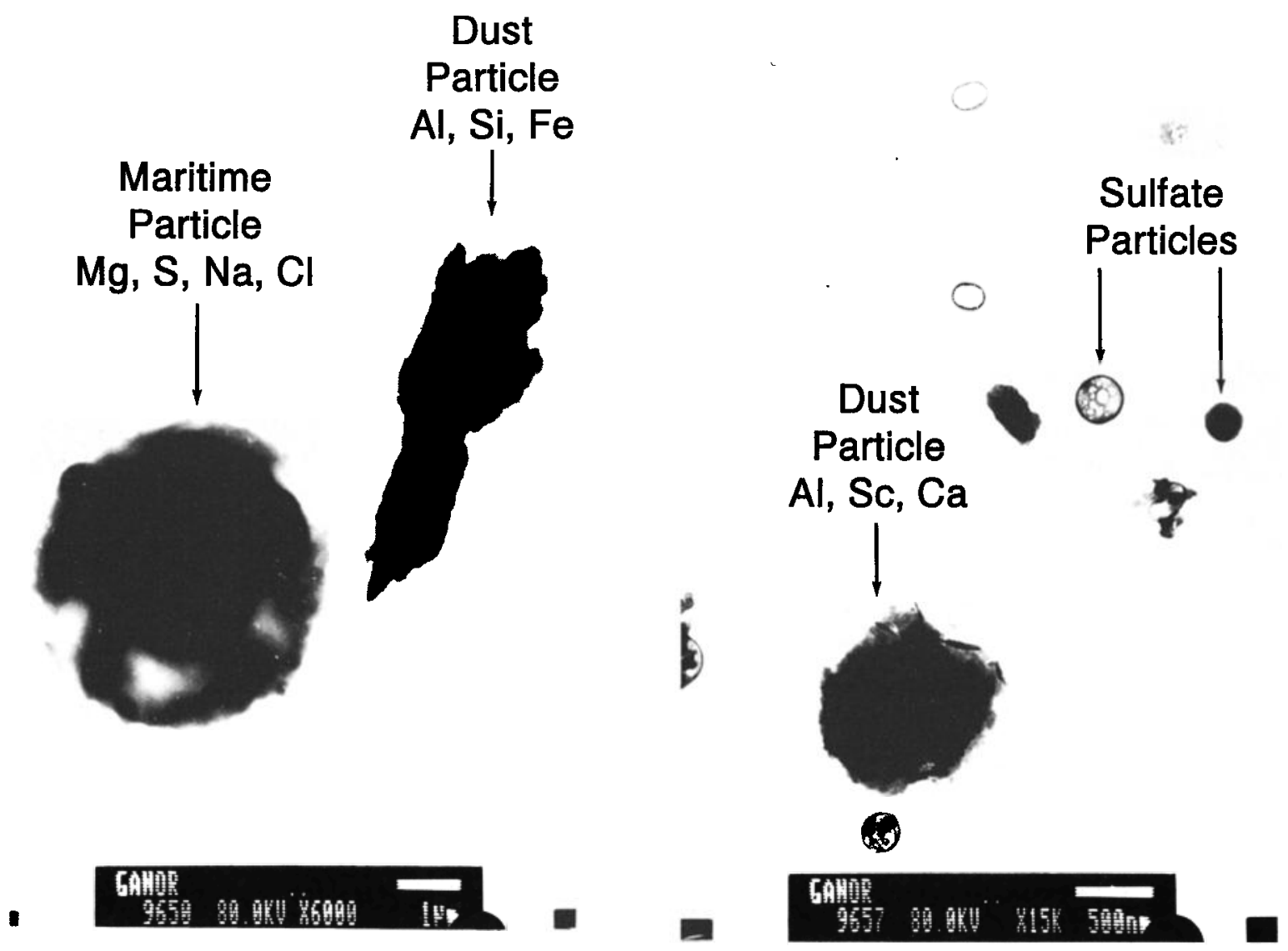

Figure 15. Example of analysis with transmission electron microscopy. On the left a maritime particle with a strong signature from $\mathrm{Na}, \mathrm{Mg}$, and $\mathrm{Cl}$ and on the right a dust particle with signatures of $\mathrm{Al}, \mathrm{Si}$, and Fe. The scales of 1 and $0.5 \mu \mathrm{m}$ are given in the right bottom corner of each figure, respectively.

Similar results were reported by Nakajima et al. [1986a] and Tanaka et al. [1990]. This may result from a lower sampling efficiency for small particles, from a possible higher concentration of small particles above the layer sampled by the aircraft and from the drying of the particles in the electron microscope analysis. Under $0.1-\mu \mathrm{m}$ radius the almucantar analysis tends to overestimate the particle concentration, a process that can add to the difference between the two size distributions. Particles above $4 \mu \mathrm{m}$ are also missing from the cascade impactor analysis, due to a cutoff in the particle size by the collection process. Note that the two spectra on May 11 , collected 1.5 hours apart, are quite similar to each other showing the repeatability of the almucantar measurements.

Comparison between the average size distribution from almucantar analysis and filter samples is shown in Figure 13b. Data are given for Europe and for the desert transition zone in Israel. The filter data include six samples in the desert transition zone and four in Eastern Europe. The filter samples taken in Eastern Europe show concentration of the small particles to be an order of magnitude higher than that in the desert transition zone. Data from the desert transition zone have a much higher concentration of large particles, with particles above $3 \mu \mathrm{m}$ missing from the filters taken in Europe. Note that the cutoff at radius of $3 \mu \mathrm{m}$, present in the aircraft data (Figure 13a) does not exist in the ground-based samples of Figure 13b due to a different collection technique.

Particle morphology and elemental composition, analyzed with the electron microscope (SEM and TEM) is shown in
Figures 14 and 15 for the desert transition zone. Small particles, radius less than $0.4 \mu \mathrm{m}$, as in the left-hand side of Figure 14 are usually spherical and show high concentration of sulfates, similar to industrial or maritime particles formed from $\mathrm{SO}_{2}$. The large particles (radius larger than $1 \mu \mathrm{m}$, right-hand side of Figure 14) are solid nonspherical particles composed of calcium carbonate and silicon (quartz). Some large particles were found to be more spherical with large concentration of sea salts (Figure 15), indicating maritime origin. Similar compositions of dust were found from analysis of samples of settling dust in Israel [Ganor et al., 1991].

\section{Conclusions}

A combination of solar transmission measurements, sky almucantar measurements and analysis with electron microscope of sampling of aerosol particles on filters, can reveal many of the physical, chemical, and optical properties of aerosol particles. In the present paper, measurements were taken in several climatic regions: desert transition zone, polluted atmosphere in Eastern and Western Europe, tropical aerosol from Brazil, and mixed aerosol from California. The following analysis was conducted:

1. Analysis of the spectral optical thickness as a measure of the total aerosol loading and of the Ångström exponent $\alpha$, a measure of the size distribution $\left(\alpha=\left(\Delta \ln \tau_{a} / \Delta \ln \lambda\right)\right.$ ). These and other aerosol properties derived from the optical measurements are of the undisturbed aerosol integrated on the vertical column. 
2. Analysis of the almucantar sky radiance for scattering angles $\leq 40^{\circ}$, to derive the aerosol size distribution. The analysis is performed with a radiative transfer inversion that accounts for multiple scattering and gaseous scattering and absorption.

3. Analysis of the sky radiance to derive the singlescattering phase function for large scattering angles that are relevant to satellite observations and for climate studies.

4. Analysis of filter samples for composition and shape of particles for different size ranges. Most of the samples were taken $1 \mathrm{~m}$ above the ground, thus not representing the whole atmospheric profile. One sample was collected from an aircraft between 1300 and $1700 \mathrm{~m}$, and two from a tower at 45 and $90 \mathrm{~m}$. The analysis by electromicroscope is done in vacuum for dry particles, thus underestimating the size of the ambient particle.

The measured volume size distributions, taken before the injection of stratospheric aerosol, show consistent two particle modes, sulfate particles with radius $\leq 0.2 \mu \mathrm{m}$, and coarse particles above $0.7 \mu \mathrm{m}$. The window in the tropospheric aerosol in this radius range was just right to observe a stable stratospheric aerosol in 1992, with a mode radius around $0.5 \mu \mathrm{m}$. The spectral dependence of the optical thickness, $\alpha$, though not a good predictor of the scattering phase function through a power law size distribution assumption is a good indicator of the ratio between the small $(0.06-0.2 \mu \mathrm{m})$ and large aerosol particles $(2-4 \mu \mathrm{m})$ except when Mount Pinatubo aerosol was present (Figure 6). This relationship was etected for the desert transition zone and for the data from Europe and California.

The measurements were used to observe the predictability of the actual single-scattering phase function at a scattering angle of $120^{\circ}$ from the derived size distribution, using Mie theory for homogeneous spheres. The results show that the effect of nonsphericity and nonhomogeneity of the particles on the single-scattering phase function is small (20\% $\pm 15 \%)$. Part of this difference may be the result of uncertainty in the surface reflectance and part in real difference in the phase functions. No relationship was found between the effect of these uncertainties on the phase function and the relative magnitude of the coarse particle mode. For the stratospheric aerosol, as expected, the phase function was very well predicted from the Mie theory. A power law assumption generated large errors in the estimated phase function of up to $50 \%$.

A combination of optical thickness and sky measurements is important to assess the direct forcing and the climatic impact of aerosol. Systematic inversion for the key aerosol types (sulfates, smoke, dust, and maritime aerosol) of the size distribution and phase function can give the relationship between the aerosol physical and optical properties. Combination with field experiments where the aerosol particles are sampled, the effect of humidity on the particles is estimated and the upward fluxes measured can be used to relate the ground-based measurements to the actual aerosol properties and their effect on the outgoing reflected sunlight. A field experiment along these principles and others was conducted recently in the eastern United States (the "Sulfate Clouds and Radiation Atlantic" experiment (SCAR A)). Other field experiments are planned.

Acknowledgments. We would like to thank A. Hamphry (a summer student in NASA/GSFC) for collecting the data in Brazil, $\mathrm{K}$. Hlavati (from the Czech Meteorological Institute, Czech Republic) for his help in the data collection in the Czech Republic., and Zev Levin from Tel Aviv University for comments on the manuscript.

\section{References}

Box, M. A., and A. Deepak, Finite sun effects on the interpretation of solar aureole, Appl. Opt., 20, 2806-2810, 1981.

Charlson, R. J., J. Langer, H. Rodhe, C. B. Leovy, and S. G. Warren, Perturbation of the northern hemispheric radiative balance by backscattering from anthropogenic sulfate aerosol, Tellus, 43(AB), 152-163, 1991.

Charlson, R. J., S. E. Schwartz, J. M. Hales, R. D. Cess, J. A. Coakley, Jr., J. E. Hansen, and D. J. Hofmann, Climate forcing by anthropogenic aerosol, Science, 255, 423-430, 1992.

Dave, J. V., and J. Gazdag, A modified Fourier transform method for multiple scattering calculations in a plane parallel Mie atmosphere, Appl. Opt., 9, 1457-1466, 1970.

Dulac, F., D. Tanré, G. Bergametti, P. Buat-Ménard, M. Desbois, and D. Sutton, Assessment of the Africa airborne dust mass over the western Mediterranean sea using Meteosat data, J. Geophys. Res., 97, 2489-2506, 1992.

Duton, E. G., and J. R. Christy, Solar radiative forcing at selected locations and evidence for global lower tropospheric cooling following the eruption of El Chicano and Pinatubo, Geophys. Res. Lett., 19, 2313-2316, 1992.

Fraser, R. S., Y. J. Kaufman, and R. L. Mahoney, Satellite measurements of aerosol mass and transport, Atmos. Environ., 18, 2577-2584, 1984.

Ganor, E., H. A. Foner, S. Brenner, E. Neeman, and N. Lavi, The chemical composition of aerosol settling in Israel following dust storms, Atmos. Environ., 25(A), 2665-2670, 1991.

Hansen, J. E., and L. D. Travis, Light scattering in planetary atmospheres, Space Sci. Rev., 16, 527-610, 1974.

Holben, B. N., T. Eck, and R. S. Fraser, Temporal and spatial variability of aerosol optical depth in the Sahel region in relation to vegetation remote sensing, Int. J. Remote Sens., I2, 1147$1165,1991$.

Holben, B. N., E. Vermote, Y. J. Kaufman, D. Tanré, and V. Kalb, Aerosols retrieval over land from AVHRR data-Application for atmospheric correction, IEEE Trans. Geosci. Remote Sens., 30, 212-222, 1992.

Huebert, B. S., G. Lee, and W. L. Warren, Airborne aerosol inlet passing efficiency measurements, J. Geophys. Res., 95, 16,36916,381, 1990.

Junge, C. E., Air Chemistry and Radiochemistry, 382 pp., Academic, San Diego, Calif., 1963.

Kaufman, Y. J., The atmospheric effect on remote sensing and its correction, chapter 9, in Optical Remote Sensing, Technology and Application, edited by G. Asrar, John Wiley, New York, 1989.

Kaufman, Y. J., Measurements of the aerosol optical thickness and the path radiance-Implications on aerosol remote sensing and atmospheric corrections, J. Geophys. Res., 98, 2677-2692, 1993.

Kaufman, Y. J., and R. S. Fraser, Light extinction by aerosols during summer air pollution, J. Appl. Meteorol., 22, 1694-1706, 1983.

Kaufman, Y. J., R. S. Fraser, and R. A. Ferrare, Satellite remote sensing of large-scale air pollution-Method, J. Geophys. Res., 95, 9895-9909, 1990.

Kaufman, Y. J., R. S. Fraser, and R. L. Mahoney, Fossil fuel and biomass burning effect on climate-Heating or cooling?, J. Clim., 4, 578-588, 1991.

King, M. D., D. M. Byrne, B. M. Herman, and J. A. Reagan, Aerosol size distribution obtained by inversion of optical depth measurements, J. Atmos. Sci., 35, 2153-2167, 1978.

King, M. D., Harshvardhan, and A. Arking, A model of the radiative properties of El Chichon stratospheric aerosol layer, $J$. Clim. Appl. Meteorol., 23, 1121-1137, 1984.

King, M. D., Y. J. Kaufman, P. Menzel, and D. Tanré, Determination of cloud, aerosol and water vapor properties from the Moderate Resolution Imaging Spectrometer (MODIS), IEEE $J$. Geosci. Remote Sens., 30, 2-27, 1992.

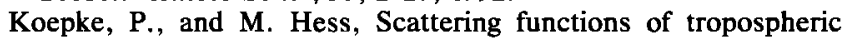
aerosol: The effects of nonspherical particles, Appl. Optics, 27, 2422-2430, 1988. 
Levin, Z., J. H. Joseph, and Y. Mekler, Properties of Sharav (Khamsin) dust-Comparison of optical and direct sampling data, J. Atmos. Sci., 37, 882-891, 1980.

Levin, Z., C. Price, and E. Ganor, The contribution of sulfate and desert aerosol to the acidification of cloud and rain in Israel, Atmos. Environ., 24(A), 1143-1151, 1990.

Mamane, Y., E. Ganor, and A. E. Dogani, Aerosol composition of urban and desert origin in the Eastern Mediterranean, I, Individual particle analysis, Water Air Soil Pollut., 14, 29-43, 1980.

May, R. K., The cascade impactor: An instrument for sampling coarse aerosols, J. Scui., Inst., 22, 187-195, 1945.

Nakajima, T., M. Tanaka, and T. Yamauchi, Retrieval of the optical properties of aerosols from aureole and extinction data, Appl. Opt., 22, 2951-2959, 1983.

Nakajima, T., T. Takamura, M. Yamano, M. Shiobara, T. Yamauchi, R. Goto, and K. Murai, Consistency of aerosol size distribution inferred from measurements of solar radiation and aureole, J. Meteorol. Soc. Jpn., 64, 765-776, 1986a.

Nakajima, T., M. Tanaka, T. Hayasaka, Y. Miyake, Y. Nakanishi, and $\mathrm{K}$. Sasamoto, Airborne measurements of the optical stratification of aerosols in turbid atmospheres, Appl. Opt., 25, 4374 4381, 1986b.

Nakajima, T., M. Tanaka, M. Yamano, M. Shiobara, K. Arao, and Y. Nakanishi, Aerosol optical characteristics in the yellow sand events observed in May, 1982 at Nagasaki, 2, Models, J. Meteorol. Soc. Jpn., 67, 279-291, 1989.

Neckel, H., and D. Labs, The solar radiation between 3300 and 12,500 A, Sol. Phys., 90, 205-258, 1984.

Penner, J. E., R. E. Dickinson, C. A. O'Neill, Effects of aerosol from biomass burning on the global radiation budget, Science, 256, 1432-1434, 1992.

Pollack, J. B., and N. Cuzzi, Scattering by nonspherical particles of size comparable to a wavelength: A semi-empirical theory and its application to tropospheric aerosols, J. Atmos. Sci., 37, 868-881, 1980.

Shaw, G. E., Inversion of optical scattering and spectral extinction measurements to recover aerosol size spectra, Appl. Opt., 18, 988-993, 1979.

Shiobara, M., T. Hayasaka, T. Nakajima, and M. Tanaka, Aerosol monitoring using a scanning spectral radiometer in Sendai, Japan, J. Meteorol. Soc. Jpn., 69, 57-70, 1991.

Stowe, L. L., R. M. Carey, and P. P. Pelegrino, Monitoring the Mt. Pinatubo aerosol layer with NOAA/11 AVHRR data, Geophys. Res. Lett., 19, 159-162, 1992.

Tanre, D., P. Y. Deschamps, C. Devaux, and M. Herman, Estimation of Saharan aerosol optical thickness from blurring effects in thematic mapper data, J. Geophys. Res., 93, 15,955-15,964, $1988 \mathrm{a}$.

Tanré, D., C. Devaux, M. Herman, R. Santer, and J. Y. Gac, Radiative properties of desert aerosols by optical ground-based measurements at solar wavelengths, J. Geophys. Res., 93, $14,223-14,231,1988 \mathrm{~b}$

Tanaka, M., T. Hayasaka, and T. Nakajima, Airborne measurements of optical properties of tropospheric aerosols over an urban area, J. Meteorol. Soc. Jpn., 68, 335-345, 1990.

Thomason, L. W., Observations of a new SAGE II aerosol extinction mode following the eruption of Mt. Pinatubo, Geophys. Res. Lett., 19, 2179-2182, 1992.

Turco, R. P., O. B. Toon, R. C. Whitten, P. Hamil, and R. G. Keesee, The 1980 eruption of Mt. St. Helen: Physical and chemical processes in the stratospheric clouds, J. Geophys. Res., $88,5299-5319,1983$.

Twitty, J. T., R. J. Parent, J. A. Weinman, and E. W. Eloranta, Aerosol size distributions: Remote determination from airborne measurements of the solar aureole, Appl. Opt., 15, 980-989, 1976.

Wang, M., and H. R. Gordon, Retrieval of columnar aerosol phase function and single scattering albedo from sky radiance over the ocean: Simulations, Appl. Opt., 32, 4598-4609, 1993.

Weinman, J. A., J. T. Twitty, S. R. Browning, and B. N. Herman, J. Atmos. Sci., 32, 577, 1975.

Yamamoto, G., and M. Tanaka, Determination of aerosol size distribution from spectral attenuation measurements, Appl. Opt. $8,447-453,1969$.

R. S. Fraser and Y. J. Kaufman, Laboratory for Atmospheres, Code 913, NASA Goddard Space Flight Center, Greenbelt, MD 20771.

E. Ganor, Institute for Environmental Research, Ministry of the Environment, and Tel Aviv University, Sackler School of Medicine, Tel Aviv, Israel 69978.

A. Gitelson and A. Karnieli, Inst. for Desert Research, Ben Gurion Univ., Sede-Boker, Israel.

B. N. Holben, Laboratory for Terrestrial Physics, Code 923, NASA Goddard Space Flight Center, Greenbelt, MD 20771.

S. Mattoo, ARC-NASA Goddard Space Flight Center, Greenbelt, MD 20771.

T. Nakajima, Center for Climate System Research, University of Tokyo, 4-6-1 Komaba, Meguru-ku, Tokyo 153, Japan.

(Received June 21, 1993; revised December 22, 1993; accepted January 20, 1994.) 